\title{
An Examination of the Composition and Microstructure of Coarse Intermetallic Particles in AA2099-T8, Including Li Detection
}

\section{Dol:}

10.1017/S1431927618000454

\section{Document Version \\ Accepted author manuscript}

Link to publication record in Manchester Research Explorer

Citation for published version (APA):

MacRae, C. M., Hughes, A. E. ., Laird, J. S., Glenn, A. M., Wilson, N. C., Torpy, A., Gibson, M. A., Zhou, X., Birbilis, N., \& Thompson, G. (2018). An Examination of the Composition and Microstructure of Coarse Intermetallic Particles in AA2099-T8, Including Li Detection. Microscopy and Microanalysis. https://doi.org/10.1017/S1431927618000454

\section{Published in:}

Microscopy and Microanalysis

\section{Citing this paper}

Please note that where the full-text provided on Manchester Research Explorer is the Author Accepted Manuscript or Proof version this may differ from the final Published version. If citing, it is advised that you check and use the publisher's definitive version.

\section{General rights}

Copyright and moral rights for the publications made accessible in the Research Explorer are retained by the authors and/or other copyright owners and it is a condition of accessing publications that users recognise and abide by the legal requirements associated with these rights.

\section{Takedown policy}

If you believe that this document breaches copyright please refer to the University of Manchester's Takedown Procedures [http://man.ac.uk/04Y6Bo] or contact uml.scholarlycommunications@manchester.ac.uk providing relevant details, so we can investigate your claim.

\section{OPEN ACCESS}




\section{Microscopy AND MicRoANALYSIS}

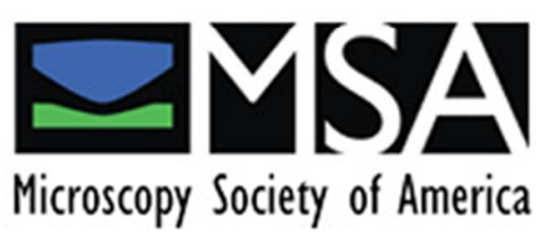

\section{An examination of the composition and microstructure of coarse intermetallic particles in AA2099-T8, including Li detection.}

\begin{tabular}{|r|l|}
\hline Journal: & Microscopy and Microanalysis \\
\hline Manuscript ID & MAM-17-099.R1 \\
\hline Manuscript Type: & Original Article \\
\hline Date Submitted by the Author: & 28-Jun-2017 \\
\hline Complete List of Authors: & $\begin{array}{l}\text { Hughes, Anthony; CSIRO, CMSE } \\
\text { MacRae, Colin; CSIRO Minerals, Microbeam Laboratory } \\
\text { Wilson, Nicholas; CSIRO Process Science and Engineering, Microbeam } \\
\text { Laboratory } \\
\text { Torpy, Aaron; CSIRO, Microbeam Laboratory } \\
\text { Glenn, A; CSIRO Minerals, Microbeam Laboratory } \\
\text { Laird, James; CSIRO Minerals, Microbeam Laboratory } \\
\text { Gibson, Mark; CSIRO, CMSE } \\
\text { Zhou, Xiaorong; University of Manchester - Sackville Street Campus, } \\
\text { School of Materials } \\
\text { Thompson, George; The University of Manchester } \\
\text { Birbilis, Nick; monash university }\end{array}$ \\
\hline \multirow{2}{*}{ Keywords: } & $\begin{array}{l}\text { Al-Cu-Li Alloy, Electron backscattered diffraction, iintermetallics, Soft X-ray } \\
\text { Emission Spectroscopy (SXES), Electron Microprobe (EPMA) }\end{array}$ \\
\hline
\end{tabular}




\section{An examination of the composition and microstructure of coarse intermetallic} particles in AA2099-T8, including Li detection.

C.M. MacRae ${ }^{1}$, A.E. Hughes ${ }^{1,2,4}$, J.S. Laird ${ }^{1}$, A.M. Glenn ${ }^{1}$, N.C. Wilson ${ }^{1}$, A. Torpy ${ }^{1}$, M.A. Gibson $^{4,5}$ X. Zhou ${ }^{3}$, N. Birbilis ${ }^{4}$ and G.E Thompson ${ }^{3}$

${ }^{1}$ CSIRO, Mineral Resources, Bayveiw Ave, Clayton, 3169 Australia.

${ }^{2}$ Institute of Frontier Materials, Deakin University, 221 Burwood Highway, Burwood VIC 3125 Australia.

${ }^{3}$ Corrosion and Protection Centre, School of Materials, The University of Manchester, Manchester M13 9PL, England, UK.

${ }^{4}$ Department of Materials Science and Engineering, Monash University, Clayton, 3800 Australia.

${ }^{5}$ CSIRO, Manufacturing, Bayview Ave, Clayton, 3169 Australia.

*Corresponding Author

CSIRO Minerals, Private Bag 10, Clayton South, 3169, Australia. Tel: 613 9542-, Fax, @csiro.au

KEYWORDS: AA2099, electron microprobe, soft X-ray emission spectroscopy, proton microprobe, Li detection, intermetallics, electron backscatter diffraction, aluminium alloys

\section{Abstract.}

Electron and proton microprobes, along with electron backscatter diffraction (EBSD) analysis were used to study the microstructure of the contemporary Al-Cu-Li alloy AA2099-T8. In electron probe microanalysis, wavelength (WDS) and energy dispersive (EDS) X-ray spectroscopy were used in parallel with soft X-ray emission spectroscopy (SXES) to characterise the microstructure of AA2099-T8. The electron microprobe was able to identify five unique compositions for constituent intermetallic (IM) particles containing combinations of $\mathrm{Al}, \mathrm{Cu}, \mathrm{Fe}, \mathrm{Mn}$ and $\mathrm{Zn}$, a sixth IM type being rich in Ti and $\mathrm{B}$ (suggesting $\mathrm{TiB}_{2}$ ), and a seventh intermetallic type containing Si. EBSD patterns for the five constituent IM particles containing $\mathrm{Al}, \mathrm{Cu}, \mathrm{Fe}, \mathrm{Mn}$ and $\mathrm{Zn}$ indicated that they were isomorphous with four well known phases in $2 x x x$ series aluminium alloys including $\mathrm{Al}_{6}(\mathrm{Fe}, \mathrm{Mn}), \mathrm{Al}_{13}(\mathrm{Fe}, \mathrm{Mn})_{4}(2$ slightly different compositions), $\mathrm{Al}_{37} \mathrm{Cu}_{2} \mathrm{Fe}_{12}$ and $\mathrm{Al}_{7} \mathrm{Cu}_{2} \mathrm{Fe}$. SXES revealed that $\mathrm{Li}$ was present in some constituent IM particles.- Al SXES mapping revealed an Al-enriched (i.e. Cu, Li- 
depleted) zone in the grain boundary network. From the EBSD analysis, the kernel average misorientation (KAM) map showed higher levels of localised misorientation in this region, suggesting greater deformation or stored energy. Proton induced X-ray emission revealed banding of the $\mathrm{TiB}_{2}$ intermetallic particles and $\mathrm{Cu}$ inter-band enrichment.

\section{Introduction}

There is ongoing interest in the transportation sector (be it aerospace, rail or automotive) for creating light-weight vehicles with the objective of increasing fuel efficiency. In the aerospace industry, light-weight is achieved through the use of contemporary aluminium (Al) alloys that incorporate lithium (Li), and form the basis of contemporary Al-Cu-Li alloys (Rioja et al. 2012) . High strength Al-Cu-Li (and Al-Cu-Mg-Li) alloys have replaced alloys such as AA2024-T3 sheet and AA7xxx series alloy plate, in aerospace applications (Dursun et al. 2014). The improved mechanical properties such as higher strength-to-weight ratio and superior corrosion resistance of $\mathrm{Al}-\mathrm{Cu}-\mathrm{Li}$ alloys mean they have considerable advantages over the alloys which they are replacing. With respect to the latter point, the corrosion performance of such alloys, whilst broadly classified, has not been mechanistically studied in great detail thus far. The so-called first and second generation versions of Li-containing Alalloys were demonstrated to be corrosion prone (Holroyd 2014) on the basis that such alloys contained $\mathrm{Li}$ as the principle alloying element and formed a number of Li-rich phases. The third generation of Li-containing alloys, however, have $\mathrm{Cu}$ as the primary alloying constituent and such alloys principally forms Cu-containing phases as opposed to Li-rich phases (Warner 2006, Dorin et al. 2014, Dursun et al. 2014, Li et al. 2016, Ott et al. 2016, Ott et al. 2017). In regards to gaining a mechanistic insight into corrosion, it is appreciated that the presence, type and size of constituent particles plays a key role (Sukiman 2012), warranting a detailed study of constituent particle types in third generation Al-Cu-Li alloys.

The general microstructure and related corrosion of $\mathrm{Al}-\mathrm{Cu}-\mathrm{Li}$ of alloys have been investigated in a number of studies (Buchheit et al. 1990, Ambat et al. 1992, Buchheit et al. 1994, Garrard 1994, Buchheit 2000, Davo et al. 2004, Davo et al. 2005, Zhou et al. 2013, Proton et al. 2014, Huang et al. 2015, Luo et al. 2016, Luo et al. 2016, Visser et al. 2016, Brodusch et al. 2017). The sub-micrometer microstructure of Al-Cu-Li alloys has recently received significant attention on the basis that precipitation sequences dictate alloy 
strength development (Dorin et al. 2014). It has been shown that upon thermal exposure from a solid solution condition, the precipitation of $\mathrm{Al}_{2} \mathrm{CuLi}\left(\mathrm{T}_{1}\right)$ and subsequently coprecipitation of $\mathrm{Al}_{2} \mathrm{CuMg}\left(\mathrm{S}^{\prime}\right)$ occurs (Ott et al. 2017) although no $\mathrm{S}^{\prime}$ was observed in this particular alloy (Ma et al. 2016). It has also been revealed that processing may influence the propensity for corrosion (Grilli et al. 2010, Carrick et al. 2013, Carrick et al. 2014, Huang et al. 2015). One issue with developing a full understanding of the microstructure-related corrosion of such alloys lies in the detection of $\mathrm{Li}$. While $\mathrm{Li}$ is a key component to the mechanical properties of these alloys, the distribution of Li in constituent IM particles and other parts of the alloy microstructure is not well characterised due to the difficulty of detecting Li.

The focus in the present study is on the characterisation of constituent and other large IM particles (typically $>1 \mu \mathrm{m}$ ) comprising significant levels of impurities and/or alloying elements, where corrosion is observed to occur. Ma et al. (Ma et al. 2011) have previously studied the same alloy examined in this present Investigation (AA2099-T8). Those authors found that constituent IM particles could be divided into three groups including; (i) high, (ii) intermediate and (iii) low Cu-containing IM particles. Moreover, wherever the high $\mathrm{Cu}$ containing phase was observed in multiphase particles, it was surrounded by the low-Cucontaining phase. At finer scales dispersoids, including Al-Cu-Mn-Li containing particles (modified $\mathrm{Al}_{20} \mathrm{Mn}_{3} \mathrm{Cu}_{2}$ ) and $\beta$-phase $\left(\mathrm{Al}_{3} \mathrm{Zr}\right.$ ) were evident as rods around $1 \mu \mathrm{m} \times 200 \mathrm{~nm}$. At even finer scales, the hardening precipitates, principally $\mathrm{T}_{1}\left(\mathrm{Al}_{2} \mathrm{CuLi}\right)$, with $\delta^{\prime}\left(\mathrm{Al}_{3} \mathrm{Li}\right)$ and $\theta^{\prime}$ $\left(\mathrm{Al}_{2} \mathrm{Cu}\right)$ have been observed in this alloy as well (laths up to $100 \mathrm{~nm}$ long and a few $\mathrm{nm}$ wide) (Ma et al. 2011).

An issue that remains unresolved is whether Li was present in the constituent IM particles. This is because $\mathrm{Li}$ is one of the most difficult elements to detect using most conventional techniques. Electron energy loss spectroscopy (EELS) (Ishida et al. 2013), Auger electron spectroscopy (AES) and energy dispersive spectroscopy with specially designed detectors (EDS) (Hovington et al. 2016) are techniques that have been used in the past to examine Li (Ishida et al. 2013, Mallinson et al. 2013) as well as Li-containing aluminium alloys (Schöberl et al. 1997, Ott et al. 2016) with some success. In this paper the authors present analysis of AA2099-T8 using soft X-ray emission spectroscopy (SXES) for Li detection. SXES studies have been reported in the past for analysis of $\mathrm{Li}$ in Li-containing aluminium alloys (Bruhwiler et al. 
1988, Shek et al. 1990, Shek et al. 1991). Here the SXES technique is combined with energy dispersive (EDS) and wavelength dispersive (WDS) X-ray spectrometry as well as electron backscatter diffraction (EBSD) for a more complete analysis of the coarse IM particles in AA2099-T8. Furthermore, these techniques are combined with proton induced X-ray emission (PIXE) to provide a different perspective to standard X-ray analysis as performed on a microprobe. Using PIXE the protons penetrate well into the material ( $\approx 60 \mu \mathrm{m})$, thus sampling a bigger volume of the material under study to the other techniques mentioned above. PIXE therefore provides new information on elemental distributions that will be discussed in this paper.

\section{Materials and Methods}

\section{Materials}

Inductively coupled plasma atomic emission spectroscopy (ICP-AES) was performed on AA2099-T8 using calibration standards appropriate to the matrix concentrations, i.e., at levels typical of the alloying concentrations in the alloy. The elemental concentrations determined are presented in Table 1 from highest to lowest.

Table 1: ICP-AES analysis of AA2099-T8 (wt.\% or ppm by weight and Al makes up the residual)

\section{Sample Preparation}

For metallographic preparation alloy specimens were mounted in a standard conductive phenolic resin then ground on 240, 600 and finally 1200 grit SiC paper. Polishing was then performed under an oil-based lubricant (Kemet Lube $M$ ) using diamond abrasive in the sequence $15,6,1$, and $0.25 \mu \mathrm{m}$ surface finish. Prior to electron back scatter diffraction (EBSD) or soft X-ray emission spectroscopy (SXES), samples were ion beam polished using a Technoorg-Linda SEMprep2, Model SC2000 ion polisher. A beam energy of $10 \mathrm{kV}, 8 \mathrm{kV}, 2 \mathrm{kV}$ and $0.4 \mathrm{kV}$ was used for 20 minutes at each stage. A sample tilt of $3.5^{\circ}$ was used for 10 and 8 $\mathrm{kV}$ and one of $5^{\circ}$ was used for 2 and $0.4 \mathrm{kV}$. This procedure was performed to minimise amorphous layers on the surface and to remove oxidation and carbonaceous compounds.

\section{Electron Backscatter Diffraction (EBSD)}

An FEI Quanta 400, field emission SEM was used to collect simultaneous EDS and EBSD datasets at an angle of $70^{\circ}$ to the horizontal. Data were collected with a Bruker eflash 
system at $15 \mathrm{kV}$ accelerating voltage. The EBSD map conditions were $1200 \times 1035$ pixels, with a step size of $0.27 \mu \mathrm{m}(270 \mathrm{~nm})$.

Individual grains were defined using a misorientation (MO) angle, $\theta$, equal to or greater than $15^{\circ}$ (Zhou et al. 2013). MOs less than $5^{\circ}$ were used for determining the level of defect density. Two methods were used: In the first method the MO of each pixel within a grain compared to the average orientation of all pixels in the same grain was determined. This method is called the grain average misorientation (GAM) map. In the second method the MO of each pixel within a grain is compared to the average orientation of its nearest neighbours. The nearest neighbours are taken from a square kernel, the size if which is user defined and was $3 \times 3$ for the current investigation. This method is called the kernel average misorientation (KAM) map. Both methods are discussed in the results section. High angle grain boundaries (HAGB) were defined as those with $\theta \geq 15^{\circ}$ and low angle grain boundaries (LAGB) were defined as those with $1^{\circ}<\theta<5^{\circ}$. Angles between these two values were designated as intermediate angle grain boundaries (IAGB).

\section{Electron Microprobe}

Electron Probe Microanalysis (EPMA) mapping was performed on two electron microprobes; a JEOL 8500F Hyperprobe and a JEOL 8530F Hyperprobe. In the former case the microprobe was equipped with two energy dispersive (ED) silicon drift X-ray detectors (SDD) and five wavelength dispersive (WD) spectrometers. At each pixel in the map an ED spectrum and a set of WD intensities were collected, forming a hyperspectral data set. In the latter case the JEOL 8530 Hyperprobe was equipped with four wavelength dispersive (WD) spectrometers, one energy dispersive (ED) spectrometer and a soft X-ray spectrometer for light element analysis. Hyperspectral data sets combined the ED, WD and soft X-ray information. Mapping on the $8500 \mathrm{~F}$ was performed at an accelerating voltage of $12 \mathrm{kV}$, with a $100 \mathrm{nA}$ beam current, a step size of $500 \mathrm{~nm}$ and a dwell time of $15 \mathrm{~ms}$ per pixel. Some additional mapping was performed at $7 \mathrm{keV}, 80 \mathrm{nA}$ with a dwell time of several seconds/pixel, to reduce the interaction volume thereby increasing surface sensitivity. The SXE spectra were collected using a modified JEOL SXE spectrometer equipped with a Jeol 50XL type grating (Takahashi et al. 2016). A Princeton PIXIS 2048B eXcelon camera was employed to detect the soft $x$-rays and spectral binning was employed so that 16 spectra were read and summed per pixel. The energy scale was calibrated using higher order $\left(2^{\text {nd }}\right.$ through to $\left.5^{\text {th }}\right)$ reflections. Additional 
internal (sample) calibration was based on assigning the Al L $\alpha$ edge to $72.7 \mathrm{eV}$ (Neddermeyer et al. 1970). The camera was operated at $-60^{\circ} \mathrm{C}$. In this mode of operation the spectral resolution as measured on $\mathrm{Al}^{\mathrm{L}_{2}}$ was $260 \mathrm{meV}$. The dwell time for each pixel in the map was set to 1.5 seconds and the instrument was controlled using the JEOL EPMA software with the SXE spectrometer driven as a slave allowing normal collection of WD spectrometer-Electron signals together with hyperspectral ED and SXE spectra. The EPMA was operated at $7 \mathrm{kV}$ with a beam current of $80 \mathrm{nA}$. The step size of the map was set to 200 $\mathrm{nm}$ and the beam was fully focused. To minimise surface contamination the maps were collected with liquid nitrogen anticontamination running. Proprietary, internally developed software was used to control the parallel collection of WDS, EDS and SXES data. All data were analysed using proprietary software, Chimage (Pownceby et al. 2007, Wilson et al. 2008). The datasets were then processed using 2-D scatter plots to identify different coarse IM particle compositions as described previously (Hughes et al. 2013). The term coarse includes constituent and other large IM particles. The mapping and analysis procedure differs from traditional automated $\mathrm{X}$-ray based image analysis techniques in that $\mathrm{a}$ hyperspectral data set is collected, rather than region of interest (ROI) mapping. Average spectra were extracted for each composition and then quantified using appropriate standards collected at the same time.

In order to achieve an accurate background shape to determine whether there was any Li in any of the constituent IM particles, it was necessary to manufacture a Li-free intermetallic composition containing $\mathrm{Al}$ and some transition metals ( $\mathrm{Cu}$ and $\mathrm{Mn}$ ) to determine whether there was any intensity contribution in the region of the SXES spectrum where the Li K $\alpha$ occurs. This compound was prepared using an argon arc melting facility. Lumps of constituent metals of 99.99+ purity were alloyed together on a water-cooled copper hearth under a reduced argon atmosphere. The alloy button was turned over and re-melted several times to ensure homogeneity of the alloying elements.

\section{Proton Microprobe}

Proton Induced X-ray Emission (PIXE) was performed at the CSIRO nuclear microprobe beamline on the pelletron housed at the University of Melbourne (Jamieson et al. 2002). 3 $\mathrm{MeV}$ protons were accelerated at the target generating X-ray emission. An aluminium filter of $100 \mu \mathrm{m}$ in thickness was placed ahead of a germanium (Ge) X-ray detector located 165 
$\mathrm{mm}$ from the sample stage for both techniques. The beam diameter was approximately 2 $\mu \mathrm{m}$. The size of analysis areas was determined by the size of the feature of interest which were approximately 50 to $100 \mu \mathrm{m}$ by 100 to $500 \mu \mathrm{m}$ with an analysis depth of $\sim 60 \mu \mathrm{m}$.

Data analysis was performed using the GeoPIXE software-. For the PIXE data, quantitative analysis was performed, by first identifying all spectral lines from a combined spectrum originating from all the pixels in a map, then performing background subtraction and finally optimising the fit. Elemental maps were generated from these data and any further analysis was undertaken from additional regions of interest determined from the maps. 


\section{Results}

\section{EBSD}

The EBSD results are summarised in Figure 1 where a backscattered electron image, grain map, GAM map and KAM map are displayed in (a), (b), (c) and (d), respectively. The backscattered image shows some grain relief, as a result of selective etching during ion beam polishing, as well as a number of coarse IM particles (bright particles). Figure 1(b) reveals the grain map as determined from EBSD where misorientations $>15^{\circ}$ were defined as separate grains. All grains in the aluminium matrix were indexed as $\alpha-A l$.

Figure 1. (a) Backscattered electron image of a region of AA2099-T8. (b) grain distribution determined on a misorientation of $15^{\circ}$ or above, (c) GAM - misorientation with respect to the average for each grain and (d) KAM - misorientation with respect to the local $3 \times 3$ matrix of pixels. All images are at the same magnification.

The AA2099 contained a broad range of grain sizes suggesting a partially recrystallized structure was observed within the field as depicted in Figure 2(a) with a large number of grains below $12 \mu \mathrm{m}$ and a diminishing number of grains with increasing grain size up to 60 $\mu \mathrm{m}$. A broad range of grain sizes is reported for extrusions of this alloy (Ma et al. 2011, Huang et al. 2015). The non-correlated misorientation distribution histogram is shown in Figure 2 (b). This histogram shows significant departure from the standard McKenzian shape for a random distribution suggesting that the microstructure still has an underlying preferred orientation, notwithstanding any recrystallization that may have taken place. Elongation of the grains in the extrusion direction results in aspect ratios ranging from 0.1 to 0.9 (Figure 2(c)). The GAM map (Figure 1(c)) shows that there are some grains which have a significant deviation of some pixels from the average orientation. These areas represent regions where subgrains or low angle boundaries have formed whose misorientation is less than the $15^{\circ}$ limit used to define a grain. These types of boundaries often form as the result of local deformation and subsequent partial recrystallization. The KAM map, Figure 1(d) however, indicates that for pixels close to each other the relative change in the degree of deformation is small. The largest deviation measured in the KAM map is at within grains is at the subgrain boundaries suggesting that most of the deformation is concentrated at these sites. 
EBSD patterns were also obtained from coarse IM particles types (as domains or individual particles). The description of these patterns is integrated below into the next section devoted to compositional characterisation.

Figure 2. Grain Statistics: (a) grain size distribution histogram for the region of AA2099-T8 depicted in Figure 1 determined using $\theta>15^{\circ}$ for grain definition. (b) non-correlated misorientation distribution histogram and (c) the grain aspect ratio. The aspect ratio should be $<1$ in the extrusion direction. All data is for the aluminium matrix and does not include other phases such as constituent IM particles.

\section{Electron Microprobe Analysis}

The electron microprobe data was used as a starting point for further analysis of the compositional domains within coarse IM particles, as well as individual coarse IM particles themselves. As in previous studies (Hughes et al. 2013), the scatter plot approach was used to determine the different types of compositional domains present in the sample. These scatter plots are formed from the hyperspectral data set where intensities of elements were available from either the WDS or EDS data. The Cu-Fe scatter plots were most useful for identifying particles containing a significant amount of $\mathrm{Cu}$ and Fe (Figure 3(a)), however, the $\mathrm{Si}-\mathrm{Ti}$ (Figure 3(b)) plot was also useful for identifying particles containing amounts of Si or Ti that were well above additive level. Full quantification for each composition presented in the Cu-Fe scatter plot was performed on the average spectra in Figure 4. These spectra were generated from the endpoints (data within the blue ellipses in Figure 3(a)) for the Al, $\mathrm{Cu}$, Fe and Mn containing constituent IM particles and from the data within the rectangle for the coarse Ti-rich and Si-rich particles. The Si-Ti scatter plot shows that the Si-containing and Ti-containing IM particles are separate from each other since their representative rectangles are essentially perpendicular and have a common origin in the matrix where the bulk levels of both $\mathrm{Si}$ and $\mathrm{Ti}$ are effectively zero. For the Si-rich particles the analysis can only be considered qualitative since the domains containing Si were too small for a quantitative analysis. Nevertheless the figures in Table 2 are representative of the average of the elements detected for this group of particles since they are un-normalised and determined from standards. The large amount of aluminium suggests the incorporation of a contribution from the $\alpha$-Al matrix.

Figure 3. Scatter plots. (a) Cu L $\alpha-F e ~ L \alpha$ : The red lines join the centre of the compositions associated with the matrix to the endpoints of each of the five $\mathrm{Cu}$-Fe compositions which are indicated in blue ellipses. The major and minor axes of these blue ellipses indicate the 
likely spread of the data based on two standard deviations. Phase assignments based on

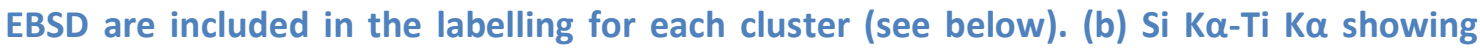
compositions that have higher levels of both $\mathrm{Si}$ and $\mathrm{Ti}$ than that based on alloy addition levels.

In all, five compositions were observed in the Cu-Fe scatter plots as shown in Figure 3(a) with the corresponding average spectra displayed in Figure 4. The compositions, expressed in at. \%, are shown in Table 2. These compositions are present as either compositional domains within particles or separate particles themselves as displayed in the compositional map in Figure 5. It should be noted that in repeated maps, the Med-Cu/High-Fe and Low$\mathrm{Cu} / \mathrm{High}-\mathrm{Fe}$ compositions were often not present indicating a heterogeneous distribution of these constituent IM particles from region-to-region on the alloy surface. The High-Cu/LowFe group form an arm running nearly parallel to the $\mathrm{Cu}$ axis. The small number of points in the High-Cu "end" composition, but significant number of points along the arm joining these compositions to the matrix cluster indicates that the particles/domains from which these points arise are small relative to the pixel size (in this context "High-Cu" covers the range from 7.5 at. \% to 15 at. \% whilst the "Low-Cu" compositions were around 3 at. \% or less). Moreover, the absence of compositions (points) between this arm and the other compositions is consistent with these particles being mostly small and separate, which is also supported by their distribution (red particles) and shape (rod-like) in the compositional maps in Figure 5. In the EBSD analysis of this composition was indexed to $\mathrm{Al}_{7} \mathrm{Cu}_{2} \mathrm{Fe}$ (Figure 6), which is consistent with a $\mathrm{Cu} / \mathrm{Fe}$ ratio of 2.4 determined from the semi-quantitative compositions shown in Table 2. The presence of additional $\mathrm{Al}, \mathrm{Cu}$ and some $\mathrm{Mg}$ is also consistent with their small size in that there is some contribution from the matrix due to the electron interaction volume. This will have the effect of slightly increasing the $\mathrm{Cu} / \mathrm{Fe}$ ratio. The presence of $\mathrm{Al}_{7} \mathrm{Cu}_{2} \mathrm{Fe}$ has previously been reported for Al-Cu-Li alloys (AA2195) by Jiang et al. (Jiang et al. 2010) and Meletis (Meletis 1987) based on qualitative EDS analysis.

All High-Fe compositions fall within a narrow spread in Fe concentration between 5.9 and 7.1 at. \% (Figure 3(a) and Table 2). The EBSD analysis of the High-Cu/High-Fe showed patterns that could be indexed to either $\mathrm{Al}_{37} \mathrm{Fe}_{12} \mathrm{Cu}_{2}$ or $\mathrm{Al}_{82.25} \mathrm{Cu}_{36.95} \mathrm{Fe}_{15.5}$ but not uniquely to either one, i.e., they may be isomorphous with the structures of these phases. Poor quality of the match with database patterns may indicate any or all of the following: (i) they are not the same phase, (ii) residual strain or (iii) effects of elemental substitution. However, 
considering the indexing in combination with the compositions (Table 2) $\mathrm{Al}_{37} \mathrm{Fe}_{12} \mathrm{Cu}_{2}$ may be a realistic assignment since its aluminium-to-transition metal (Al/TM) ratio with a stoichiometry of 3.2 is close to the Al:(transition metal) ratio of 2.6 for $\mathrm{Al}_{37} \mathrm{Fe}_{12} \mathrm{Cu}_{2}$. This phase sometimes occurred as shared domains with the High-Cu/Low-Fe $\left(\mathrm{Al}_{7} \mathrm{Cu}_{2} \mathrm{Fe}\right)$ with a morphology suggesting that the latter nucleated on the former. This can probably be viewed as a process that involves Fe-consumption during precipitation from the melt during ingot cooling since the solubility of Fe in solid Al is low (Hatch 1984). The local consumption of Fe, combined with high solubility and diffusion of $\mathrm{Cu}$ and perhaps a higher local $\mathrm{Cu}$ concentration results in the precipitation of the $\mathrm{High}-\mathrm{Cu} / \mathrm{Low}-\mathrm{Fe}\left(\mathrm{Al}_{7} \mathrm{Cu}_{2} \mathrm{Fe}\right)$ phase on the High-Cu/High-Fe phase. (Note that the compositions of phases under discussion here should be taken from Table 2 and not from the stoichiometry of the structures identified using EBSD, i.e., since the phases in Table 2 are only isomorphous with the structures).

Both the upper and lower arms of the Med-Cu/High-Fe particles were indexed to $\mathrm{Al}_{13}(\mathrm{Fe}$, $\mathrm{Mn})_{4}$ using EBSD which is consistent with their Al:TM ratio around 3 (Table 2). The upper arm of the Med-Cu/High-Fe composition was predominantly observed as individual small particles, occasionally with $\mathrm{Al}_{7} \mathrm{Cu}_{2} \mathrm{Fe}$, and less occasionally with the lower arm composition. On the other hand, the lower arm generally appeared in larger particles along with the Low$\mathrm{Cu} / \mathrm{High}-\mathrm{Fe}$ compositions described below. The different morphology of these two closely related compositions suggests different origins.

The last composition from the Cu-Fe scatter plot is the cluster labelled Low-Cu/High-Fe. As stated above this composition was often found with the upper arm of the Med-Cu/High-Fe composition, but also often found as individual particles. The EBSD suggests that this composition is isomorphous with $\mathrm{Al}_{6}(\mathrm{Fe}, \mathrm{Mn})(11 / 12$ bands detected), which is consistent with the observed composition (Al:TM ratio) reported in Table 2. The exact ratio of Al:TM might be difficult to determine since the $\mathrm{Al}_{6}(\mathrm{Fe}, \mathrm{Mn})$ is an example of the more general orthorhombic $(\mathrm{Al}, \mathrm{Cu})_{6}(\mathrm{Fe}, \mathrm{Mn}, \mathrm{Cu})$ phase (Phragmen 1950). In cases where the lower arm of the Med-Cu/high-Fe $\left(\mathrm{Al}_{13}(\mathrm{Fe}, \mathrm{Mn})_{4}\right)$ was paired with the Low-Cu/High-Fe composition $\left(\mathrm{Al}_{6}(\mathrm{Fe}, \mathrm{Mn})\right)$ it appeared that the latter phase may nucleate on the former phase given that it was present as smaller domains on the larger particles. (From this point forward the scatter plot designation will be used since it represents the elemental stoichiometry in the constituent IM particles, but, for reference, the EBSD assignment will follow in brackets.) 
The variation in elemental composition of the particles compared to the strict stoichiometry of the EBSD assignment can be seen in Figure 7 which shows three colour composition maps for two constituent intermetallic particles and their corresponding EBSD assignment. The constituent IM particle in the top of the image comprises both the Med-Cu/High-Fe phase $\left(\mathrm{Al}_{13}(\mathrm{Fe}, \mathrm{Mn})_{4}\right.$, magenta in the EBSD map inset) and the Low-Cu/High-Fe phase $\left(\mathrm{Al}_{6}(\mathrm{Fe}, \mathrm{Mn})\right.$, grey in EBSD map inset) in a particle that contains multiple grains. The constituent particle in the bottom of the image is a single Med-Cu/High-Fe domain which was indexed to $\mathrm{Al}_{13}(\mathrm{Fe}$, $\mathrm{Mn})_{4}$. Comparing the colour mixing from the EDS it is clear that there are different Cu levels in the $\mathrm{Al}_{13}(\mathrm{Fe}, \mathrm{Mn})_{4}$ domain at the top, and that this particle has less Fe than the particle at the bottom, which has an even mix of $\mathrm{Cu}, \mathrm{Fe}, \mathrm{Mn}$.

While the five compositions based on the Cu-Fe scatter plot have a similar range of compositions to the three compositional types reported by Ma et al. (Visser et al. 2016), the scatter plot reveals some subtle variations. Specifically, the scatter plot (Figure 3(a)) shows that the "variable Cu and Low-Cu" compositions reported by Ma et al. (Visser et al. 2016) can be divided into four compositionally similar groups which all have similar Fe content in the range 5.5 to 7.1 at.\%. Ma et al.'s high Cu appears to correspond to the group in this study labelled High-Cu/High-Fe $\left(\mathrm{Al}_{37} \mathrm{Fe}_{12} \mathrm{Cu}_{2}\right)$, their "variable-Cu" appears to correspond to the Med-Cu/High-Fe (upper), Med-Cu/High-Fe (lower) $\left(\mathrm{Al}_{13}(\mathrm{Fe}, \mathrm{Mn})_{4}\right)$ and their "low $\mathrm{Cu}^{\prime}$ " to the Low-Cu/High-Fe grouping reported here $\left(\mathrm{Al}_{6}(\mathrm{Fe}, \mathrm{Mn})\right)$. It would appear that because the High-Cu/Low-Fe group $\left(\mathrm{Al}_{7} \mathrm{Cu}_{2} \mathrm{Fe}\right)$ comprised small particles it may not have been included in the earlier study. The ability to differentiate these subtleties using the scatter plot approach highlights the difference between point analyses and large area map analyses. In the case of Ma et al. only constituent IMs were selected for analysis whereas in this study all pixels in the maps are analysed thus capturing features that might not otherwise have been observed by Ma et al. (Ma et al. 2011).

Figure 4. Average spectra for (from bottom to top): High-Cu/Low-Fe, High-Cu/High-Fe, Med-Cu/High-Fe (upper arm), Med-Cu/High-Fe (lower arm), Low-Cu/High-Fe, Sicontaining, Ti-containing. $\mathrm{L}=$ lower arm and $\mathrm{U}=$ upper arm. All spectra were collected at $10 \mathrm{keV}$.

Figure 5. (a) Map of compositional domains over a large area. (b) Magnification of the region within the dashed square indicated in (a) with compositions shown. All the phase are defined from the scatter plots in Figure 3. 
Figure 6. EBSD patterns from various particles or particle domains. The $\mathrm{Al}_{6}(\mathrm{Fe}, \mathrm{Mn})$ is the pattern from the top left intermetallic domain labelled $A$ in Figure 7, $\mathrm{Al}_{37} \mathrm{Fe}_{12} \mathrm{Cu}_{2}$ is from Region $\mathrm{B}, \mathrm{Al}_{13}(\mathrm{Fe}, \mathrm{Mn})_{4}$ is from the bottom particle and $\mathrm{Al}_{7} \mathrm{Cu}_{2} \mathrm{Fe}$ is from the small rod-like particle (red) labelled $D$. All these patterns were obtained by spot analysis on the individual compositional domains for an extended time. The bottom pattern is for a Ti-rich particle and was extracted from a map with overlying $\mathrm{TiB}_{2}$ patterns.

The microprobe analyses (Table 2 and Figure 4) show that there were more elements incorporated into the constituent IM particles and domains than those nominated based on the stoichiometry from the EBSD results, indicating either elemental substitution (Phragmen 1950, Chen et al. 2016, Grushko et al. 2016) or nano-domains (Sha et al. 2011, Feng et al. 2013, Parvizi et al. 2017) of different composition. Those elements observed in many constituent IM particles included $\mathrm{Si}, \mathrm{Mg}$ and $\mathrm{Zn}$ at some level. Whilst the scatter plot approach minimises the inclusion of signal from the matrix by the choice of endpoint compositions (points inside the blue ellipses are well clear of the matrix points in Figure 3), for small particles (such as $\mathrm{Al}_{7} \mathrm{Cu}_{2} \mathrm{Fe}$ ) it cannot entirely eliminate the signal from the matrix since the endpoint composition itself will move towards the matrix group in small particles. In the case of $\mathrm{Mg}$ for example, it is likely to come from the matrix, and there will also be additional Al signal from the matrix. In the other cases, the elements are likely to arise solely from the constituent IM particles that are larger so there is little contribution from the matrix.

Figure 7. Three colour EDS elemental maps for $\mathrm{Cu}$, Fe and $\mathrm{Mn}$. Inserts are EBSD maps for the larger particles. Magenta represents $\mathrm{Al}_{13}(\mathrm{Fe}, \mathrm{Mn})_{4}$, grey represents $\mathrm{Al}_{6}(\mathrm{Fe}, \mathrm{Mn})$ and yellow is $\alpha$-Al.

In addition to those compositions identified in the Cu-Fe scatter plots a small population of two different types of constituent IM particles were observed in the Si-Ti scatter plot. The $\mathrm{Si}$-Ti scatter plot was chosen to represent these two compositions, because it demonstrates that the Si-rich and Ti-rich particles are independent of each other since both "boxes" are perpendicular to each other and converge to the origin. EDS spectra collected at lower accelerating voltage showed the presence of B suggesting that these coarse IM particles may be $\mathrm{TiB}_{2}$. They also contain some $\mathrm{Al}$ and other elements such as $\mathrm{Cu}, \mathrm{Fe}, \mathrm{Mn}$ and $\mathrm{Zn}$. The $\mathrm{TiB}_{2}$ particularly, are unlikely to contain the transition metal as substitutional elements, so the detection of these elements may indicate that they have small inclusions within them. $\mathrm{Ti}$ would normally be present as a grain refiner in the form of $\mathrm{TiB}_{2}$ or $\mathrm{Al}_{3} \mathrm{Ti}$, in the latter case in 
a similar fashion to $\mathrm{Zr}$ in $\mathrm{Al}_{3} \mathrm{Zr}$ (Hatch 1984). The presence of $\mathrm{Ti}$ as larger constituent IM particles suggests that it is not optimally dispersed as the grain refining phase. Finally, there was a population of Si-containing constituent IM particles. Their position on the scatter plot and the spectrum, presented in Figure 3 and Figure 4, respectively, indicate that they are a distinct group from the other coarse Ti-containing particles. They contained Al and small amounts of $\mathrm{Ti}$ and other transition metals. Some oxygen was detected with these particles suggesting a slightly greater susceptibility to oxidation than the other constituents which had only very low levels of oxygen. These Ti- and Si-containing IM phases have not previously been reported for this alloy batch. Whilst these particles showed EBSD patterns, no match for these patterns could be found.

Table 2. Semi Quantitative compositions (at. \%) determined for the different compositional types of constituent IM particles in AA2099-T3 as defined in Figures 3 and 4. (TM=transition metal).

\section{Soft X-ray Emission Spectroscopy}

Soft X-ray emission (SXE) spectroscopy was used to examine Li in the matrix and also determine whether $\mathrm{Li}$ was present in the constituent IM particles. A sum, soft X-ray spectrum from a large area of the sample is displayed in Figure 8 . The sum spectrum has a number of peaks associated with elements detected on the surface including, Li K (54.2 eV), Al $L(72.7 \mathrm{eV})$, and a second order reflection of the $\mathrm{CK}$ line at $137 \mathrm{eV}$ (the figures in brackets are the edge positions). Figure 9 displays an SXE spectrum for the Al-Li region of AA2099-T8 as well as a magnification of the Li peak. The Al La peak (Figure 9(a)) shows an edge at 72.7 $\mathrm{eV}$ which is attributed to emission from the Fermi level (Bruhwiler et al. 1988); features at lower energies in the spectrum represent the density of states. There is a sharp peak just below the Fermi level at $72.2 \mathrm{eV}$ and a broad emission band at lower energies. The peak at $72.2 \mathrm{eV}$ is associated with dynamical screening of the core hole by valence electrons with significant $s$ and $d$ contributions (Ovcharenko et al. 2011, Ovcharenko et al. 2013). Features in the Al L $\alpha$ emission band are not well understood but are related to X-ray emission from multi-electron transitions and screening around the core-hole created during photoemission from the Al $2 p$ level. Auger transitions will also be involved in the process and contribute intensity below $72.7 \mathrm{eV}$. Surface oxidation may contribute intensity to this region, but there were no $\mathrm{O} \mathrm{K}$ peaks in the spectra in Figure 8 (although the significance of this contribution is low at the excitation energies used here (Shulakov et al. 1993)). Moreover, from the EDS, for 
most sites there was very little oxygen detected (Figure 4)). No oxygen was detected in SXE either. For the spectrum from the matrix, the majority of the signal comes from the aluminium in the $\alpha$-Al. Changes in shape of this region of the peak have been suggested to be a useful diagnostic tool for determining the degree of precipitate hardening, for example, in AA2091 (Liu et al. 2016).

Figure 8: Soft X-ray sum spectrum of AA2099-T8 showing the Li K and AI L Fermi edges. The small peak at $137 \mathrm{eV}$ is associated with a second order reflection of the C K edge.

With respect to the Li K spectrum in Figure 9(b), the Fermi edge occurs $54.2 \mathrm{eV}$ peaking at $53.7 \mathrm{eV}$ which is typical for Al-Cu-Li alloys (Bruhwiler et al. 1988). There is also broadening extending to the lower energy side of the peak, which, like the $A l L_{2,3}$ edge is related to the density of states near the Fermi edge. However, the spectroscopy of the Li peak is slightly less complex than the Al L peak since K-levels have very little contribution from Auger processes that increase the level of broadening to lower energies in other shells like the Lshell (Ovcharenko et al. 2014). A peak in the intensity at $52.6 \mathrm{eV}$ and below has been reported to be due to perturbing effects of a 1 s core-hole during ionisation in pure $\mathrm{Li}$ (Goodings 1965). However, when $\mathrm{Li}$ is alloyed, for example with $\mathrm{Mg}$, then the maximum intensity occurs at the Fermi edge (Rajput et al. 1994). Broadening to the low energy side of the peak in the region ( 49 to $50 \mathrm{eV}$ ) has been attributed to a range of effects including $p$ state contributions to the density of states (Goodings 1965) but has also been reported to be due to $s$ to $p$ hybridization based on the Linear Combination of Atomic Orbitals (LCAO) modelling (Liu et al. 2016). On the other hand, Li compounds (oxides and halides) can show peak splitting and have intense peaks at higher energies (in the vicinity of $60 \mathrm{eV}$ ), which are not observed here (Tsuji et al. 2001). In this study, as with the Al peak, the Li peak can be considered to be primarily associated with one part of the microstructure, in this case the hardening precipitate $T_{1}$ phase $\left(\mathrm{Al}_{2} \mathrm{CuLi}\right)$ and is essentially used for determining the presence or absence of $\mathrm{Li}$ in different parts of the microstructure. There will also be some contribution from the dispersoids since they have been reported to contain Li (Ma et al. 2011).

SXE spectra for different domains of the constituent IM particles are displayed in Figure 10. The shape of the soft X-ray Al L emission lines from the constituent IM particles showed significant differences from the matrix as well as variations between individual constituent 
IM particles or domains at energies between 60 and $75 \mathrm{eV}$ (c.f. Figure 9(a) to Figure 10). All the constituent IM particles containing $\mathrm{Al}, \mathrm{Cu}, \mathrm{Fe}$ and $\mathrm{Mn}$ showed more than one peak within the range 65 to $74 \mathrm{eV}$ with variations in the separation and relative height of these features. The additional intensity in this region represents much higher electron density near the Fermi level than for the Al L $\alpha$ edge from the matrix which is not surprising since there is a considerable transition metal contribution to the density of states from the $3 \mathrm{~d}$ and $4 \mathrm{~s}$ levels. Whilst an explanation of the exact origins of these variations is beyond the scope of this paper, these differences represent "signatures" for each compositional type and could possibly be used for fingerprinting purposes based on peak positions. The peak separation might also be used for fingerprinting since the splitting between the two peaks changes from type to type, varying in the range 3.1 to $3.8 \mathrm{eV}$ between peaks.

The presence or absence of $\mathrm{Li}$ in the constituent IM particles cannot be confirmed from Figure 10. Some of the particles, such as $\mathrm{Cu}$-poor/Fe-rich $\left(\mathrm{Al}_{6}(\mathrm{Fe}, \mathrm{Mn})\right)$ and the $\mathrm{Cu}$-rich/Ferich $\left(\mathrm{Al}_{37} \mathrm{Fe}_{12} \mathrm{Cu}_{2}\right)$ do show a very slight (almost imperceptible) bump in the spectrum around the energy of the Li Ka peak suggesting the possible presence of Li. However, there might equally be unknown intensity contributions to the Li region resulting from other elements in the IM compounds. To investigate this possibility a separate intermetallic compound was prepared with a composition of $\mathrm{Al}_{76.8} \mathrm{Fe}_{17.7} \mathrm{Cu}_{5.5}$ but without any Li. SXE spectra for both this compound as well as the relevant IMs in the AA2099 are presented in Figure 11. It is clear that the reference compound has no intensity contribution to the Li Ka region (47.5 to $55 \mathrm{eV}$ ) indicating that the intensity observed in this region from the constituent IM particles is due to the presence of $\mathrm{Li}$. This result was repeated for both constituent IM particles investigated. It was not possible, however, to determine how much $\mathrm{Li}$ was in these particles since the matrix effects are unknown for these compositions and structures.

Figure 9. Soft X-ray spectra of (a) Al-Li region and (b) magnification of the Li region (Ka). The Li spectrum has been smoothed using adjacent averaging over 5 points (i.e. \pm 2 points).

Figure 10. Soft X-ray Li and Al spectra from different IM compositions. The SXES spectra has been smoothed using adjacent averaging extending over \pm 2 points).

Figure 11. SXES spectra of two types of (a) $\mathrm{Al}_{6}\left(\mathrm{Fe}, \mathrm{Mn}\right.$ ) and (b) $\mathrm{AL}_{37} \mathrm{Fe}_{12} \mathrm{Cu}_{2}$ from the AA2099 compared (in both cases) with synthesised $\mathrm{Al}_{76.8} \mathrm{Mn}_{17.7} \mathrm{Cu}_{5.5}$. The SXES of the IM 
particles from the AA2099 show evidence of Li which is not present in the reference phase $\left(\mathrm{Al}_{76.8} \mathrm{Mn}_{17.7} \mathrm{Cu}_{5.5}\right)$.

A further complication with $\mathrm{Li}$ detection is in determining where the $\mathrm{Li}$ is within the intermetallic compound since it appeared to vary from position to position and also IM to IM within the same compositional type of IM particles. Figure 12 shows maps and SXE spectra from different region in an $\mathrm{Al}_{6}(\mathrm{Fe}, \mathrm{Mn}) \mathrm{IM}$ particle. The BSE image shows some bright areas and dark areas, with the bright areas being an $\mathrm{Al}_{13}(\mathrm{Fe}, \mathrm{Mn})_{4}$ domain (which is ignored in the analysis for $\mathrm{Li}$ in this example). The rest of the $\mathrm{IM}$ is $\mathrm{Al}_{6}(\mathrm{Fe}, \mathrm{Mn})$. The total SXES intensity map is shown in Figure 12 (b). Since the major peak in the SXE spectrum is the Al $L \alpha$, those regions of the map with the greatest amount of $\mathrm{Al}$ (ie, the matrix) show the highest intensity of SXE. Since the constituent IM particle contains less Al than the matrix, it has a lower SXE intensity and shows light blue to black contrast within the $\mathrm{Al}_{6}(\mathrm{Fe}, \mathrm{Mn})$ region even within regions of even contrast in the BSE image. All points from within the $\mathrm{Al}_{6}(\mathrm{Fe}, \mathrm{Mn})$ region fall in the same group in the scatter plot (blue colour) indicating that (a) they have the same $\mathrm{Cu} / \mathrm{Fe}$ ratio and (b) there is no contamination from the underlying alloy. If there was contaminant signal from the alloy then this would be indicated in the scatter plot by the points moving towards the matrix grouping instead of being in the Low-Cu/HighFe grouping. The Chimage software used for the post processing of this dataset allows different pixels within the map to be independently selected. It then automatically integrates the spectra behind these pixels producing a sum spectrum of the selection. By selecting pixels, first from the black region and then from the brighter areas of the blue region in Figure 12 (b), it has been possible to obtain a qualitative assessment of the presence or absence of $\mathrm{Li}$ in these regions of the IM particle. The selected pixels are shown in Figure 12 (c) where those coloured red are from the brighter blue areas of Figure 12 (b) and produce the sum spectrum labelled "Bright" in Figure 12 (e) and those pixels coloured blue/green in Figure 12 (c) are from the black areas of Figure 12 (b) and produce the sum spectrum labelled "Dark" in Figure 12 (e). These figures clearly show that the intermetallic particle does contain $\mathrm{Li}$, that the $\mathrm{Li}$ distribution within the particle is inhomogeneous and that the black regions of Figure 12 (b) contain more Li than the brighter blue areas. This suggests Li-containing domains within the particle. 
Figure 12. Variation in Li content in $\mathrm{Al}_{6}(\mathrm{Fe}, \mathrm{Mn})$. The BSE image shows some bright regions related to $\mathrm{Al}_{7} \mathrm{Cu}_{2} \mathrm{Fe}$ domains, grey regions and dark areas. Total SXES intensity shows light blue to black contrast within the IM particle even within regions of even BSE contrast. The SXE spectra show that the dark regions have higher levels of Li than the rest of the IM particles excluding the $\mathrm{Al}_{7} \mathrm{Cu}_{2} \mathrm{Fe}$ domains.

A similar analysis of a High- $\mathrm{Cu} / \mathrm{High}-\mathrm{Fe}\left(\mathrm{Al}_{37} \mathrm{Fe}_{12} \mathrm{Cu}_{2}\right) \mathrm{IM}$ particle is shown in Figure 13. The total SXES intensity shows light blue to black contrast within the IM particle where there is no contrast variation in the BSE image. All points from within the particle fall in the same group (blue) in the scatter plot which indicates again that (a) they have the same $\mathrm{Cu} / \mathrm{Fe}$ ratio and (b) that there is no interference from the underlying alloy as with the particle above. The SXE spectra show that the darker regions have slightly higher levels of Li than the lighter regions again suggesting domains within the particle with slightly more Li than the rest of the particle. The peak in the darker region shows some structure on the low energy side and appears to mimic the $\mathrm{Al} \mathrm{L \alpha} \mathrm{peak}\left(\mathrm{Al}_{37} \mathrm{Fe}_{12} \mathrm{Cu}_{2}\right.$, Figure 10) and may represent the Li Ka density of states splitting.

Figure 13. Variation in Li content in $\mathrm{Al}_{37} \mathrm{Fe}_{12} \mathrm{Cu}_{2}$. The BSE image shows some bright areas and dark areas. Total SXES intensity shows light blue to black contrast within the IM particles even within regions of contrast in the BSE image. The SXE spectra show that the dark regions have higher levels of Li than the brighter regions.

\section{EBSD, EDS, and Soft X-Ray Mixed Mapping}

In addition to the detailed analyses of the coarse IM particles, other aspects of the microstructure were revealed using the soft X-ray analysis. Figure 14 shows a mixture of SXES and EBSD data collected on the same region as that shown in Figure 7 (the data in Figure 14 is inverted compared to that shown in Figure 7). This SXES dataset was collected after the EBSD dataset. The sample had to be repolished between the two experiments to remove carbon contamination from the EBSD analysis and any oxide layer that may have formed when the sample was exposed to air during insertion into and removal from the SEM. Consequently, there is a slight mismatch between the two datasets with respect to the shape of the particles and the exact position of the grain boundaries. Notwithstanding this, a comparison between the two datasets is still valid since the amount of material removal was small and the grain boundaries evident in the EBSD map are clearly the same boundaries evident in the SXES map. 
Figure 14 (a) shows an AI L $\alpha$ SXES map. There is evidence of a network of Al-rich boundaries across the surface of this map similar to the grain structure shown in the EBSD map of Figure 14(b). One such grain is highlighted in the dashed white box. The grain boundary, enriched in Al, is clearly seen in the Al La SXES map of Figure 14 (a). The same grain and grain boundary are clearly evident inside white dashed box shown in the EBSD data of Figure 14(b)-(d). The grain itself is most clearly seen as the light green feature in the centre of Figure 14(c). The KAM map highlights some substructure in the "grain" outlined in the dashed white rectangle. The grain map presented in Figure 14(c) was determined using a misorientation angle of $9^{\circ}$ indicating that the grain is defined only by intermediate angle grain boundaries (IAGB) and not HAGBs, however the substructure within the grain is only refined for angles of $0.5^{\circ}$ indicating LAGBs. Consequently, it would appear that the structure observed in the Al L $\alpha$ Map is associated with IAGB and HAGBs. The origin of the "Alenrichment" is likely to be due to the formation of grain boundary precipitates in the form of the $T_{1}$ phase which have been reported at the grain boundary in this alloy (Ma et al. 2016). The Cu map Figure 14(e) shows some decoration of the grain boundary with particles containing $\mathrm{Cu}$ and the $\mathrm{Cu}-\mathrm{Al}-\mathrm{Li}$ map also shows decoration of the grain boundary with particles that contain both $\mathrm{Cu}$ and $\mathrm{Li}$ suggesting the presence of the $\mathrm{T}_{1}$ phase at the grain boundary. (Of course there are particles within grains as well as would be expected). These data seems to suggest that the Al La map captures the depletion of $\mathrm{Cu}$ and $\mathrm{Li}$ in the grain boundaries that results when the $T_{1}$ phase is formed. Since the boundary is depleted in $\mathrm{Cu}$ and $\mathrm{Li}$, it is correspondingly enriched in Al compared to the matrix.

Another feature observed using the microprobe is displayed in Figure 15(a) and shows the distribution of $\mathrm{Zr}$ detected using WDS which appears in patches across the surface. Figure 15(b) shows $\mathrm{Cu}, \mathrm{Zr}$ and $\mathrm{Al}$ in a three-colour map using the $\mathrm{Cu}$ L $\alpha$ (EDS), $\mathrm{Zr}$ L $\alpha$ (WDS) and Al L $\alpha$ SXES maps. In this case the depleted grain boundary region is apparent in red, many of the constituent IM particles are depicted in blue and the patches of $\mathrm{Zr}$ appear in green. Whilst there appears to be some correlation of the $\mathrm{Zr}$ patch structure with the grain structure (as defined by the depleted grain boundary network in red), there are also areas where this is clearly not the case, so the origin of this patchy Zr structure is not clear from this data.

Figure 14. Mixed SXES, EDS, WDS and EBSD data (a) AI L $\alpha$ map and (b) KAM map with the dashed rectangle highlighting a large grain near the constituent IM particle. (c) EBSD grain 
map with HAGBs (in this case $\theta>9^{\circ}$ ) (d) EBSD grain map for LAGBs $\left(\theta=0.5^{\circ}\right),(e) \mathrm{Cu}$ L $\alpha$ EDS map highlighting the presence of $\mathrm{Cu}$ particles decorating the grain boundary, (f) 3-colour image incorporating Cu L $\alpha$ EDS, AI L $\alpha$ (SXES), and Li K $\alpha$ (SXES). The microprobe data were collected on the same area, but after a light polish to remove carbon contamination. White arrows point to $\mathrm{T}_{1}$ precipitates.

Figure 15. Mixed EDS, WDS and Soft X-ray maps. (a) Zr L $\alpha$ map, (b) 3-colour image incorporating $\mathrm{Cu}$ L $\alpha$ (EDS), $\mathrm{Zr} \operatorname{L} \alpha$ (SXES) and AI L $\alpha$ (SXES), (EDS).

Proton Microprobe - PIXE

PIXE is not commonly used in the study of aluminium alloys. However, PIXE has previously been used by the authors in the study of corrosion of AA2024-T3 and is useful for probing deeper into samples particularly through corrosion products (Szymanski et al. 2002, Boag et al. 2005, Boag et al. 2010). An example of a PIXE spectrum of AA2099 is displayed in Figure 16(a). For the AA2099-T8 examined here, the PIXE spectrum shows elements with atomic numbers from $\mathrm{Al}$ and above. Elements detected using PIXE include major elements such as $\mathrm{Al}, \mathrm{Ti}, \mathrm{Mn}, \mathrm{Fe}, \mathrm{Cu}, \mathrm{Zn}$ and $\mathrm{Zr}$. In addition to elements expected on the basis of the alloy composition (Table 1), Ga was also detected at low levels. The Ga K $\alpha$ lines were present as a shoulder on the $\mathrm{Zn} \mathrm{K \alpha}$ lines. The presence of $\mathrm{Ga}$ in aluminium alloys has previously been reported by $\mathrm{Wu}$ and Hebert (Wu et al. 1996). The region of the spectrum around $\mathrm{Zr}$ also has a considerable contribution from detector pile-up peaks. Selected PIXE elemental maps collected from the polished surface of AA2099-T8 are shown in Figure 17. It can be seen that the majority of the alloying elements are incorporated into the constituent IM particles. No attempt was made to quantify the constituent IM particle compositions from the maps because of the large sampling depth, meaning that individual pixels could potentially contain contributions from both surface and a considerable number of subsurface particles as well as the matrix. The contribution of subsurface particles dominates the PIXE maps as can be seen by comparing the particle density in the electron microprobe image (Figure 5), where the sampling depth is of the order of a micron, with Figure 17 where the sampling depth is an order of magnitude greater ( $\approx 60 \mu \mathrm{m}$; N.B. both images are of a similar scale).

Figure 16. PIXE sum spectrum. The markers beneath the elemental identification indicate the position of the two major peaks for the element ( $K \alpha$ and $K \beta$ lines). The red marker indicates where there is a relevant pile-up contribution to the spectrum. There is also 
pileup elsewhere in the spectrum but it is several orders of magnitude smaller than the signal.

The PIXE maps show the distribution of all coarse particles in the alloy. In addition, the high sensitivity and depth of analysis PIXE means that other features are evident in the maps that would not be easily seen in either WDS or EDS performed on a microprobe or in a scanning electron microscope. For example, the Cu elemental map in Figure 17 shows Cu-enrichment bands running diagonally across the map. These bands, which are approximately $50 \mu \mathrm{m}$ in width, appear to comprise a high density of small particles parallel to the extrusion direction. Moreover, there appears to be similar banding in the Ti map. In this case the banding in the Ti map arises from the arrangement of larger particles $\left(\mathrm{TiB}_{2}\right)$ described in the electron microprobe section. These two bands sit adjacent to one another suggesting that one is mutually exclusive of the other. The origin of these features is not clear, but their size suggests that they may be related to shear band structures formed during extrusion. Shear bands are defined as structures where there is an accumulation of dislocations. It has been reported that $\mathrm{T}_{1}$ phase may precipitate in these regions during artificial aging (Huang et al. 2016)

Figure 17. $\mathrm{Zn}, \mathrm{Mn}, \mathrm{Fe}, \mathrm{Zr}$, Ti and $\mathrm{Cu}$ PIXE maps of AA2099-T8. The $\mathrm{Cu}$ and Ti maps show evidence of banding. In the case of $\mathrm{Cu}$ there appears to be a high density of Cu-containing particles whereas in the case of Ti the bands comprise Ti-containing particles.

\section{Discussion}

The results collected and presented herein are unique on the basis of the methods employed and the ability to identify light elements including Li. The question of $\mathrm{Li}$ incorporation into constituent IM particles has therefore been addressed in this study. Specifically, some constituent IM particles containing $\mathrm{Al}, \mathrm{Cu}, \mathrm{Fe}, \mathrm{Mn}$ and $\mathrm{Zn}$ identified in the $\mathrm{Cu}$-Fe scatter plot in Figure $3\left(\mathrm{Al}_{13}(\mathrm{Fe}, \mathrm{Mn})_{4}, \mathrm{Al}_{6}(\mathrm{Fe}, \mathrm{Mn}), \mathrm{Al}_{37} \mathrm{Fe}_{12} \mathrm{Cu}_{2}\right.$ and $\left.\left.\mathrm{Al}_{7} \mathrm{Cu}_{2} \mathrm{Fe}\right)\right)$ appear to have some Li incorporation based on the SXES measurements. The two examples identified here where Li was detected include the Low-Cu/High-Fe type $\left(\mathrm{Al}_{6}(\mathrm{Fe}, \mathrm{Mn})\right)$ and the High-Cu/High-Fe type $\left(\mathrm{Al}_{37} \mathrm{Fe}_{12} \mathrm{Cu}_{2}\right)$. The amount of $\mathrm{Li}$ appeared to vary from particle to particle with some particles having no apparent Li. Moreover, the Li distribution within some particles varied showing regions with and without any Li. 
The detection of $\mathrm{Li}$ in these particles raises several questions. Firstly, from a metallurgical perspective and from thermodynamic phase prediction, there is no expectation that Li will be present in constituent IM particles that form at high temperatures in the alloy melt. So if Li were present as a substituent in such constituent IM particles, it is not clear for which elements they would substitute. Secondly, if the $\mathrm{Li}$ is present in precipitates then the formation and nature of those precipitates would need a focused study, and complementary TEM analyses. The dark regions which are "Li-rich" in Figure 12 and Figure 13 are typically $1 \mu \mathrm{m}$ in size which is similar in size to domains of different composition reported for constituent IM particles in AA2024-T3 (Hughes et al. 2013) but the EBSD appears to suggest that these have homogenous crystallography even across compositional gradients. Clearly the scatter plot eliminates interaction volume effects, so it can be said with some confidence that the $\mathrm{Li}$ is present in the detection volume. The cleaning treatment might also be examined in terms of contamination by the matrix over the surface of the constituent IM particles, however the effect would be expected to be the same for different individual particles and seems an unlikely explanation for variable concentration of $\mathrm{Li}$ on these particles. Clearly, there is room for more work in this area and along with quantification is part of an ongoing study requiring the development of standards and measurement of mass absorption coefficients, which represents a large body of requisite work.

Indeed, such studies merit pursuit, as the presence of a heterogeneous Li distribution could have important implications for corrosion. The presence of $\mathrm{Li}$ in the High-Cu/High-Fe particles $\left(\mathrm{Al}_{37} \mathrm{Fe}_{12} \mathrm{Cu}_{2}\right)$ may explain the unusual corrosion behaviour of this particle type reported by $\mathrm{Ma}$ et al. (Ma et al. 2015) in AA2099-T8 where these particles would be expected to show cathodic activity, but appeared to dealloy. The small level of Li detected in these particles is similar to small amounts of $\mathrm{Mg}$ in constituent IM particles containing $\mathrm{Al}$, $\mathrm{Cu}, \mathrm{Fe}$ and $\mathrm{Mn}$ in AA2024-T3 (Hughes et al. 2013). Both these studies indicate that small amounts of alkali metals are present in constituent IM particles, but neither study reveals whether they are incorporated into the lattice structure or occur as nano-domains within the particles as observed in other studies of intermetallic particles in 2xxx alloys. Unlike modern AA2024-T3 sheet product, the structure and composition of the group of $\mathrm{Al}, \mathrm{Cu}, \mathrm{Fe}$, 
Mn-containing constituent IM particles in AA2099-T8 are more readily associated with well defined phases related to ternary and quaternary phase diagrams from the literature (Phragmen 1950, Mondolfo 1976). This may be because this AA2099-T8 has 3 to 4 percent, by weight, less alloying and impurity elements (in fact, notably lower concentrations of impurities) than AA2024-T3, and considerably less Si, which appears to be associated primarily with only the Si-rich phase. This may mean that the formation of the $\mathrm{Al}, \mathrm{Cu}, \mathrm{Fe}, \mathrm{Mn}$ containing constituent IM particles are more closely related to phases from ternary or quaternary phase diagrams. Where there is significant $\mathrm{Si}$ then the phase assemblage becomes more complicated and some of the $\mathrm{Al}, \mathrm{Cu}, \mathrm{Fe}$ and $\mathrm{Mn}$ containing phases result from the decomposition of Si-containing phases (Phragmen 1950, Sperry 1956, Mondolfo 1976, Hatch 1984).

The presence of the $\mathrm{TiB}_{2}$ intermetallic particles being readily detected is also unique, as such particles are often difficult to detect using conventional methodologies. From the PIXE results it can be inferred that there are volumes of the alloy that have higher density of $\mathrm{TiB}_{2}$ particles than adjacent volumes which PIXE suggest have a higher level of $\mathrm{Cu}$. The influence of these types of regions on mechanical and corrosion behaviour is unknown.

The EBSD results reveal that the size and structure of the grain boundary network through the KAM map is similar to the size and structure of the network observed in the Al L map suggesting that both these structures arise from the same feature in the microstructure of the alloy, i.e. the grain boundary network. The apparent overlap of the KAM map features with the Al-enrichment suggests a higher level of disorder in the region of grain boundaries than elsewhere within the grains. An Al-enriched sub-grain boundary network (noting that the grain boundary itself is decorated with precipitate phases) is likely to have different electrochemical properties to the grain interior as discussed previously (Meletis 1987, Proton et al. 2014, Ott et al. 2016), however the exact nature of the electrochemistry will depend on whether the loss of solute such as $\mathrm{Cu}$ and $\mathrm{Li}$ is a result of precipitation in the grain boundary of particles (e.g., most likely $\mathrm{T}_{1}$-types or possibly $\theta$-types) or diffusion of solute away from the grain boundary (Proton et al. 2014, Ma et al. 2016, Ott et al. 2016). It is worth noting here that there is a high density of precipitates reported for the grain boundaries in this material (Ma et al. 2011) suggesting that for this material the T8 temper 
may still be sensitive to grain boundary attack as confirmed previously in like alloys (Ma et al. 2015, Ma et al. 2016, Ott et al. 2017).

The detected patches of Zr-enrichment observed using the electron microprobe, presents a new observation of elemental distribution in aluminium alloys. The addition of Zr occurs for grain size control during homogenisation via the presence of $\mathrm{Al}_{3} \mathrm{Zr}$. The thermal stability of $\mathrm{Al}_{3} \mathrm{Zr}$ is considered excellent, and thus unlikely to undergo any further changes during processing such that the "Zr-patch" formation likely represents the distribution of $\mathrm{Al}_{3} \mathrm{Zr}$ particles

\section{Conclusions}

In this study an electron microprobe equipped with SXES detection was employed to investigate constituent particles in the Al-Cu-Li alloy AA2099-T8, in addition to other microstructural features of the alloy. This unique approach was undertaken to provide a quantitative study of the coarse IM particle composition in AA2099, including lithium presence and distribution. It was done in the context of understanding the alloy performance in terms of physical properties, such as corrosion, which required discrete study. Specifically it was determined that there exist at least five different compositions that contain some (or all) of the following elements, $\mathrm{Al}, \mathrm{Cu}, \mathrm{Fe}, \mathrm{Mn}$ and $\mathrm{Zn}$, and of which are isomorphous with one of the following four phases: $\mathrm{Al}_{13}\left(\mathrm{Fe}, \mathrm{Mn}_{4}, \mathrm{Al}_{6}(\mathrm{Fe}, \mathrm{Mn}), \mathrm{Al}_{37} \mathrm{Fe}_{12} \mathrm{Cu}_{2}\right.$ and $\mathrm{Al}_{7} \mathrm{Cu}_{2} \mathrm{Fe}$. Analysis from scatter plots indicates that two compositions are associated with $\mathrm{Al}_{13}(\mathrm{Fe}, \mathrm{Mn})_{4}$. From SXES, some constituent IM particles from either $\mathrm{Al}_{6}(\mathrm{Fe}, \mathrm{Mn})$ or $\mathrm{Al}_{37}$ $\mathrm{Fe}_{12} \mathrm{Cu}_{2}$ contained $\mathrm{Li}$, but full quantification remains the basis of important future work. In addition, Ti-rich and Si-containing coarse IM particles were found which contain small amounts of transition metals. SXES mapping revealed an "Al-enriched" grain boundary network as well as patches containing marginally higher levels of $\mathrm{Zr}$ than surrounding regions. The "Al-enriched" grain boundaries are attributed to $\mathrm{Cu}$ and Li-depletion resulting from either $T_{1}$ formation in the grain boundary network concomitant with experimental data on this alloy (Ma et al. 2016). Interestingly, the width of the depleted network seems similar to the width of the grain boundary network as revealed through the local misorientation angle calculated using the KAM map. Finally, PIXE analysis revealed other 
structures in the alloy in the form of banding of alternating copper and $\mathrm{TiB}_{2}$ coarse $\mathrm{IM}$ particles. The origin of this banding is unclear but may be related to shear banding.

\section{Acknowledgements}

The authors acknowledge the support of the Australian Research Council, LE130100087. Professor Nick Birbilis would like to thank Woodside Energy for their support. 


\section{References}

Ambat, R. and E. S. Dwarakadasa (1992). "The influence of $\mathrm{pH}$ on the corrosion of medium strength aerospace alloys 8090, 2091 and 2014." Corrosion Science 33(5): 681-690.

Boag, A., R. J. Taylor, T. H. Muster, N. Goodman, D. McCulloch, C. Ryan, B. Rout, D. Jamieson and A. E. Hughes (2010). "Stable pit formation on AA2024-T3 in a NaCl environment." Corrosion Science 52(1): 90-103.

Boag, A. P., D. G. McCulloch, D. N. Jamieson, S. M. Hearne, A. E. Hughes, C. G. Ryan and S. K. Toh (2005). "Combined nuclear microprobe and TEM study of corrosion pit nucleation by intermetallics in aerospace aluminium alloys." Nuclear Instruments \& Methods in Physics Research Section B-Beam Interactions with Materials and Atoms 231: 457-462.

Brodusch, N., F. Voisard and R. Gauvin (2017). "About the contrast of $\delta^{\prime}$ precipitates in bulk Al-Cu-Li alloys in reflection mode with a field-emission scanning electron microscope at low accelerating voltage." Journal of Microscopy.

Bruhwiler, P. A., J. L. Wagner, B. D. Biggs, Y. Shen, K. M. Wong, S. E. Schnatterly and S. J. Poon (1988). "Soft-x-ray, heat-capacity, and transport measurements on icosahedral and crystalline alloys." Physical Review B 37(11): 6529-6532.

Buchheit, R. G. (2000). The electrochemistry of theta (Al2Cu), S (Al2CuMg) and T-1 (Al2CuLi) and localized corrosion and environment assisted cracking in high strength $\mathrm{Al}$ alloys. Aluminium Alloys: Their Physical and Mechanical Properties, Pts 1-3. E. A. Starke, T. H. Sanders and W. A. Cassada. 3313: $1641-1646$.

Buchheit, R. G., J. P. Moran and G. E. Stoner (1990). "LOCALIZED CORROSION BEHAVIOR OF ALLOY2090 - THE ROLE OF MICROSTRUCTURAL HETEROGENEITY." Corrosion 46(8): 610-617.

Buchheit, R. G., J. P. Moran and G. E. Stoner (1994). "ELECTROCHEMICAL-BEHAVIOR OF THE T-1 (AL2CULI) INTERMETALLIC COMPOUND AND ITS ROLE IN LOCALIZED CORROSION OF AL-2-PERCENTLI-3-PERCENT-CU ALLOYS." Corrosion 50(2): 120-130.

Carrick, D. M., S. C. Hogg and G. D. Wilcox (2013). Corrosion of an advanced Al-Cu-Li alloy for aerospace applications. Materials Science Forum. 765: 629-633.

Carrick, D. M., S. C. Hogg and G. D. Wilcox (2014). "Investigation into the impact of lithium additions on the corrosion response of Al-Cu alloys for aerospace applications." Corrosion Management(122): 14-18.

Chen, A., L. Zhang, G. Wu, Y. Peng and Y. Li (2016). "Effect of Mn addition on microstructure and mechanical properties of cast Al-2Li-2Cu-0.8Mg-0.4Zn-0.2Zr alloy." Journal of Materials Research 31(2): 250-258.

Davo, B., A. Conde and J. J. de Damborenea (2005). "Inhibition of stress corrosion cracking of alloy AA8090 T-8171 by addition of rare earth salts." Corrosion Science 47(5): 1227-1237.

Davo, B. and J. J. de Damborenea (2004). "Use of rare earth salts as electrochemical corrosion inhibitors for an Al-Li-Cu (8090) alloy in 3.56\% NaCl." Electrochimica Acta 49(27): 4957-4965. Dorin, T., A. Deschamps, F. D. Geuser and C. Sigli (2014). "Quantification and modelling of the microstructure/strength relationship by tailoring the morphological parameters of the T1 phase in an Al-Cu-Li alloy." Acta Materialia 75: 134-146.

Dursun, T. and C. Soutis (2014). "Recent developments in advanced aircraft aluminium alloys." Materials and Design 56: 862-871.

Feng, Z., Y. Yang, B. Huang, X. Luo, M. Li, Y. Chen, M. Han, M. Fu and J. Ru (2013). "HRTEM and HAADF-STEM tomography investigation of the heterogeneously formed S (Al2CuMg) precipitates in Al-Cu-Mg alloy." Philosophical Magazine 93(15): 1843-1858.

Garrard, W. N. (1994). "Corrosion behavior of aluminum-lithium alloys." Corrosion 50(3): 215-225. Goodings, D. A. (1965). "Interpretation of the soft X-ray emission spectrum of lithium metal." Proceedings of the Physical Society 86(1): 75-85.

Grilli, R., M. A. Baker, J. E. Castle, B. Dunn and J. F. Watts (2010). "Localized corrosion of a 2219 aluminium alloy exposed to a 3.5\% NaCl solution." Corrosion Science 52(9): 2855-2866. 
Grushko, B., D. Pavlyuchkov, S. B. Mi and S. Balanetskyy (2016). "Ternary phases forming adjacent to Al3Mn-Al4Mn in Al-Mn-TM (TM = Fe, Co, Ni, Cu, Zn, Pd)." Journal of Alloys and Compounds 677: 148162.

Hatch , J. E. (1984). Aluminium: Porperties and Physical Metallurgy, ASM International.

Holroyd, N. J. H., Scamans, G.M., Newman, R.C., Vasudevan, A.K. (2014). Aluminum-Lithium Alloys: Processing, Properties and Applications. N. E. Prasad, Gokhale, A.A., Wanhill, R.J.H. Oxford, Butterworth-Heinemann, Elsevier.

Hovington, P., V. Timoshevskii, S. Burgess, H. Demers, P. Statham, R. Gauvin and K. Zaghib (2016).

"Can we detect Li K X-ray in lithium compounds using energy dispersive spectroscopy?" Scanning 38(6): 571-578.

Huang, W., Y. Ma, X. Zhou, X. Meng, Y. Liao, L. Chai, Y. Yi and X. Zhang (2015). "Correlation between localized plastic deformation and localized corrosion in AA2099 aluminum-lithium alloy." Surface And Interface Analysis.

Huang, W., Y. Ma, X. Zhou, X. Meng, Y. Liao, L. Chai, Y. Yi and X. Zhang (2016). "Correlation between localized plastic deformation and localized corrosion in AA2099 aluminum-lithium alloy." Surface and Interface Analysis 48(8): 838-842.

Hughes, A. E., A. M. Glenn, N. Wilson, A. Moffatt, A. J. Morton and R. G. Buchheit (2013). "A consistent description of intermetallic particle composition: An analysis of ten batches of AA2024T3." Surface And Interface Analysis 45: 1558-1563.

Ishida, N. and D. Fujita (2013). "Chemical-state imaging of Li using scanning Auger electron microscopy." Journal of Electron Spectroscopy and Related Phenomena 186(1): 39-43.

Jamieson, D. N., B. Rout, R. Szymanski, P. Spizzirri, A. Sakellariou, W. Belcher and C. G. Ryan (2002). "The new Melbourne nuclear microprobe system." Nuclear Instruments and Methods in Physics Research, Section B: Beam Interactions with Materials and Atoms 190(1-4): 54-59.

Jiang, N., X. Gao and Z. Q. Zheng (2010). "Microstructure evolution of aluminum-lithium alloy 2195 undergoing commercial production." Transactions of Nonferrous Metals Society of China (English Edition) 20(5): 740-745.

Li, J. F., N. Birbilis, D. Y. Liu, Y. L. Chen, X. H. Zhang and C. Cai (2016). "Intergranular corrosion of Znfree and Zn-microalloyed Al-xCu-yLi alloys." Corrosion Science 105: 44-57.

Liu, Y., P. Visser, X. Zhou, S. B. Lyon, T. Hashimoto, M. Curioni, A. Gholinia, G. E. Thompson, G. Smyth, S. R. Gibbon, D. Graham, J. M. C. Mol and H. Terrynb (2016). "Protective film formation on AA2024T3 Aluminum Alloy by leaching of lithium carbonate from an organic coating." Journal of the Electrochemical Society 163(3): C45-C53.

Luo, C., S. P. Albu, X. Zhou, Z. Sun, X. Zhang, Z. Tang and G. E. Thompson (2016). "Continuous and discontinuous localized corrosion of a $2 x x x$ aluminium-copper-lithium alloy in sodium chloride solution." Journal of Alloys and Compounds 658: 61-70.

Luo, C., X. Zhang, X. Zhou, Z. Sun, Z. Tang, F. Lu and G. E. Thompson (2016). "Characterization of Localized Corrosion in an Al-Cu-Li Alloy." Journal of Materials Engineering and Performance 25(5): 1811-1819.

Ma, Y., X. Zhou, W. Huang, G. E. Thompson, X. Zhang, C. Luo and Z. Sun (2015). "Localized corrosion in AA2099-T83 aluminum-lithium alloy: The role of intermetallic particles." Materials Chemistry and Physics 161: 201-210.

Ma, Y., X. Zhou, Y. Liao, Y. Yi, H. Wu, Z. Wang and W. Huang (2016). "Localised corrosion in AA 2099T83 aluminium-lithium alloy: The role of grain orientation." Corrosion Science.

Ma, Y., X. Zhou, G. E. Thompson, T. Hashimoto, P. Thomson and M. Fowles (2011). "Distribution of intermetallics in an AA 2099-T8 aluminium alloy extrusion." Materials Chemistry and Physics 126(12): 46-53.

Mallinson, C. F., J. E. Castle and J. F. Watts (2013). "Analysis of the Li KLL auger transition on freshly exposed lithium and lithium surface oxide by AES." Surface Science Spectra 20(1): 113-127.

Meletis, E. I. (1987). "Microstructure and stress-corrosion cracking relationship in an AlLiCuZr alloy." Materials Science and Engineering 93(C): 235-245. 
Mondolfo, L. F. (1976). Akuminum Alloys: Structure and Properties. London, Butterworth \& Co. Neddermeyer, H. and G. Wiech (1970). "Soft X-ray L-emission spectrum of aluminium." Physics Letters A 31(1): 17-18.

Ott, N., S. K. Kairy, Y. Yan and N. Birbilis (2017). "Evolution of Grain Boundary Precipitates in an AlCu-Li Alloy During Aging." Metallurgical and Materials Transactions A: Physical Metallurgy and Materials Science 48(1): 51-56.

Ott, N., Y. Yan, S. Ramamurthy, S. Kairy and N. Birbilis (2016). "Auger electron spectroscopy analysis of grain boundary microchemistry in an Al-Cu-Li alloy." Scripta Materialia 119: 17-20.

Ovcharenko, R. E., I. I. Tupitsyn, V. G. Kuznetsov and A. S. Shulakov (2011). "Study of mechanisms of formation of X-Ray emission bands in crystals by the density functional method: The Mg L 2,3 bands in metal and in MgO." Optics and Spectroscopy (English translation of Optika i Spektroskopiya) 111(6): 940-948.

Ovcharenko, R. E., I. I. Tupitsyn, E. P. Savinov, E. N. Voloshina, Y. S. Dedkov and A. S. Shulakov (2014). "Calculation of the $\mathrm{X}$-Ray emission $\mathrm{K}$ and $\mathrm{L} 2,3$ bands of metallic magnesium and aluminum with allowance for multielectron effects." Journal of Experimental and Theoretical Physics 118(1): 11-17. Ovcharenko, R. E., I. I. Tupitsyn, E. P. Savinov, E. N. Voloshina, B. Paulus, Y. S. Dedkov and A. S. Shulakov (2013). "Specific many-electron effects in X-ray spectra of simple metals and graphene." Physical Chemistry Chemical Physics 15(18): 6749-6756.

Parvizi, R., A. E. Hughes, M. Y. Tan, R. K. W. Marceau, M. Forsyth, P. Cizek and A. M. Glenn (2017). "Probing corrosion initiation at interfacial nanostructures of AA2024-T3." Corrosion Science 116: 98109.

Phragmen, G. (1950). "On the Phases Occurring in Alloys of Aluminium with Copper, Magnesium, Manganese, Iron and Silicon." The Journal of the Institute of Metals 77: 489-553.

Pownceby, M. I., C. M. MacRae and N. C. Wilson (2007). "Mineral characterisation by EPMA mapping." Minerals Engineering 20(5): 444-451.

Proton, V., J. Alexis, E. Andrieu, J. Delfosse, A. Deschamps, F. De Geuser, M. C. Lafont and C. Blanc (2014). "The influence of artificial ageing on the corrosion behaviour of a 2050 aluminium-copperlithium alloy." Corrosion Science 80: 494-502.

Rajput, S. S., R. M. Singru and R. Prasad (1994). "KKR-CPA calculations of density of states and soft Xray emission from disordered Li-Mg alloys." Solid State Communications 90(5): 339-342.

Rioja, R. J. and J. Liu (2012). "The evolution of Al-Li base products for aerospace and space applications." Metallurgical and Materials Transactions A: Physical Metallurgy and Materials Science 43(9): 3325-3337.

Schöberl, T. and S. Kumar (1997). "Depletion of lithium due to surface oxidation: An investigation of an Al • Li-sheet by Auger-spectroscopy." Journal of Alloys and Compounds 255(1-2): 135-141.

Sha, G., R. K. W. Marceau, X. Gao, B. C. Muddle and S. P. Ringer (2011). "Nanostructure of aluminium alloy 2024: Segregation, clustering and precipitation processes." Acta Materialia 59(4): 1659-1670.

Shek, M. L., J. Hrbek, T. K. Sham and G. Q. Xu (1990). "A soft X-ray study of the interaction of oxygen with Li." Surface Science 234(3): 324-334.

Shek, M. L., T. K. Sham, J. Hrbek and G. Q. Xu (1991). "A soft X-ray study of a LiS surface compound." Applied Surface Science 48: 332-336.

Shulakov, A. S., A. P. Stepanov, A. P. Brajko, H. Müller, H. Kirchmayr and A. Szasz (1993). "Surface oxidation of dilute AIMgSi alloys." Journal of Electron Spectroscopy and Related Phenomena 62(4): 351-358.

Sperry, P. (1956). "The Intermetallic Particles in 2024 Aluminum Alloy." Transactions of theAmerican Society for Metals 48: 904-918.

Sukiman, N. L., Zhou, X., Birbilis, N., Hughes, A.E., Mol, J.M.C., Garcia, S.J., Zhou, X., and Thompson, G.E. (2012). Durability and Corrosion of Aluminium and Its Alloys: Overview, Property Space, Techniques and Developments Aluminium Alloys - New Trends in Fabrication and Applications. Z. Ahmad. Rijeka, Intech Publications. 
Szymanski, R., D. N. Jamieson, A. E. Hughes, A. Mol, S. van der Zwaag and C. G. Ryan (2002). "Filiform corrosion imaged beneath protection layers on Al alloys." Nuclear Instruments \& Methods in Physics Research Section B-Beam Interactions with Materials and Atoms 190: 365-369.

Takahashi, H., T. Murano, M. Takakura, S. Asahina, M. Terauchi, M. Koike, T. Imazono, M. Koeda and T. Nagano (2016). Development of soft X-ray emission spectrometer for EPMA/SEM and its application. IOP Conference Series: Materials Science and Engineering.

Tsuji, J., K. Kojima, S. Ikeda, H. Nakamatsu, T. Mukoyama and K. Taniguchi (2001). "Li K-edge spectra of lithium halides." Journal of Synchrotron Radiation 8(2): 554-556.

Visser, P., H. Terryn and J. M. C. Mol (2016). Aerospace coatings. Springer Series in Materials Science. 233: 315-372.

Warner, T. (2006). "Recently-developed aluminium solutions for aerospace applications." Material Science Forum 519-521: 1271-1278.

Wilson, N., C. MacRae and A. Torpy (2008). "Analysis of combined multi-signal hyperspectral datasets using a clustering algorithm and visualisation tools." Microscopy and Microanalysis 14(SUPPL. 2): 764-765.

Wu, X. and K. Hebert (1996). "Development of Surface Impurity Segregation during Dissolution of Aluminum." Journal of the Electrochemical Society 143(1): 83-91.

Zhou, X., C. Luo, Y. Ma, T. Hashimoto, G. E. Thompson, A. E. Hughes and P. Skeldon (2013). "Grainstored energy and the propagation of intergranular corrosion in AA2xxx aluminium alloys." Surface And Interface Analysis 45(10): 1543-1547. 
Table 1: ICP-AES analysis of AA2099-T8 (wt.\% or ppm by weight and Al makes up the residual)

\begin{tabular}{|c|c|}
\hline Element & $\begin{array}{c}\text { Concentration } \\
\text { (wt.\% or ppm by weight) }\end{array}$ \\
\hline & Weight \% \\
\hline $\mathrm{Cu}$ & 2.83 \\
\hline $\mathrm{Li}$ & 1.62 \\
\hline $\mathrm{Zn}$ & 0.72 \\
\hline $\mathrm{Mg}$ & 0.30 \\
\hline $\mathrm{Mn}$ & 0.29 \\
\hline K & 0.06 \\
\hline \multirow[t]{2}{*}{$\mathrm{Fe}$} & 0.04 \\
\hline & ppm by weight \\
\hline $\mathrm{Zr}$ & 985 \\
\hline $\mathrm{Ti}$ & 245 \\
\hline $\mathrm{Si}$ & 180 \\
\hline $\mathrm{Ni}$ & 22.3 \\
\hline $\mathrm{Cr}$ & 15 \\
\hline V & 12 \\
\hline $\mathrm{Na}$ & 3.3 \\
\hline $\mathrm{Ag}$ & 1.5 \\
\hline
\end{tabular}


Table 2:. Semi Quantitative compositions (at. \%) determined for the different compositional types of constituent IM particles in AA2099-T3 as defined in Figures 3 and 4. (TM=transition metal).

\begin{tabular}{l|c|c|c|c|c|c|c|c|c|c}
\hline IM Description & $\begin{array}{c}\text { EBSD } \\
\text { Assignment }\end{array}$ & $\begin{array}{c}\mathrm{Al} \text { :TM } \\
\text { ratio }\end{array}$ & $\mathrm{Al}$ & $\mathrm{Si}$ & $\mathrm{Cu}$ & $\mathrm{Fe}$ & $\mathrm{Mn}$ & $\mathrm{Zn}$ & $\mathrm{Ti}$ & $\mathrm{Mg}$ \\
\hline $\begin{array}{l}\mathrm{Cu} \text { Poor Fe } \\
\text { Rich }\end{array}$ & $\mathrm{Al}_{6}(\mathrm{Fe}, \mathrm{Mn})$ & 5.2 & 83.9 & 0.0 & 3.4 & 7.1 & 4.4 & 1.1 & 0.1 & 0.0 \\
Med Cu-Fe (L) & $\mathrm{Al}_{13}(\mathrm{Fe}, \mathrm{Mn})_{4}$ & 3.1 & 75.2 & 0.0 & 9.3 & 6.8 & 7.0 & 1.7 & 0.0 & 0.0 \\
Med Cu-Fe (U) & $\mathrm{Al}_{13}(\mathrm{Fe}, \mathrm{Mn})_{4}$ & 3.1 & 75.6 & 0.0 & 11.5 & 6.9 & 3.9 & 2.0 & 0.0 & 0.0 \\
Cu-Fe rich & $\mathrm{Al}_{37} \mathrm{Fe}_{12} \mathrm{Cu}_{2}$ & 3.2 & 76.2 & 0.0 & 14.6 & 5.5 & 1.3 & 2.1 & 0.0 & 0.1 \\
Cu-rich No Fe & $\mathrm{Al}_{7} \mathrm{Cu}_{2} \mathrm{Fe}$ & 7.9 & 87.8 & 0.0 & 7.9 & 0.2 & 1.1 & 1.9 & 0.1 & 0.4 \\
Ti-Rich & $\mathrm{TiB}_{2}$ & $\mathrm{Al}: \mathrm{Ti}=4$ & 70.3 & 0.2 & 1.7 & 0.7 & 0.2 & 0.8 & 17.8 & 0.4 \\
Si-Rich & $\mathrm{N.D.}^{1}$ & $\mathrm{Al}: \mathrm{Si}=$ & 81.6 & 10.9 & 1.2 & 3.1 & 0.2 & 0.9 & 1.5 & 0.6 \\
\hline
\end{tabular}

${ }^{1}$ Not determined because no matching pattern was found. 

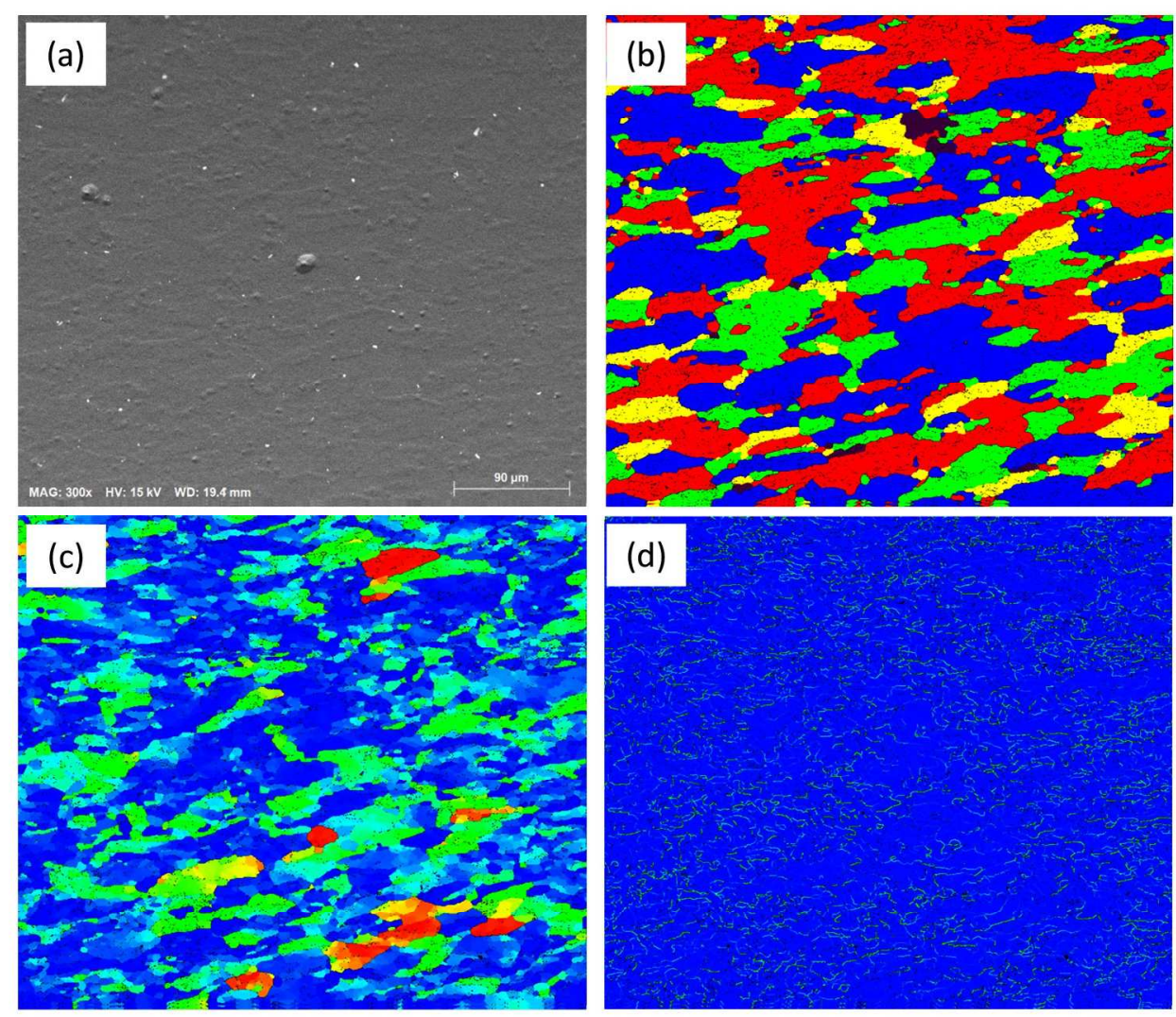

Figure 1. Grain Statistics: (a) grain size distribution for the region of AA2099-T8 depicted in Figure 1 determined using $\theta>15^{\circ}$ for grain definition. (b) Non-correlated misorientation distribution histogram and (c) the grain aspect ratio. The aspect ratio should be $<1$ in the extrusion direction. All data is for the aluminium matrix and does not include other phases such as constituent IM particles.

$204 \times 175 \mathrm{~mm}(300 \times 300$ DPI) 

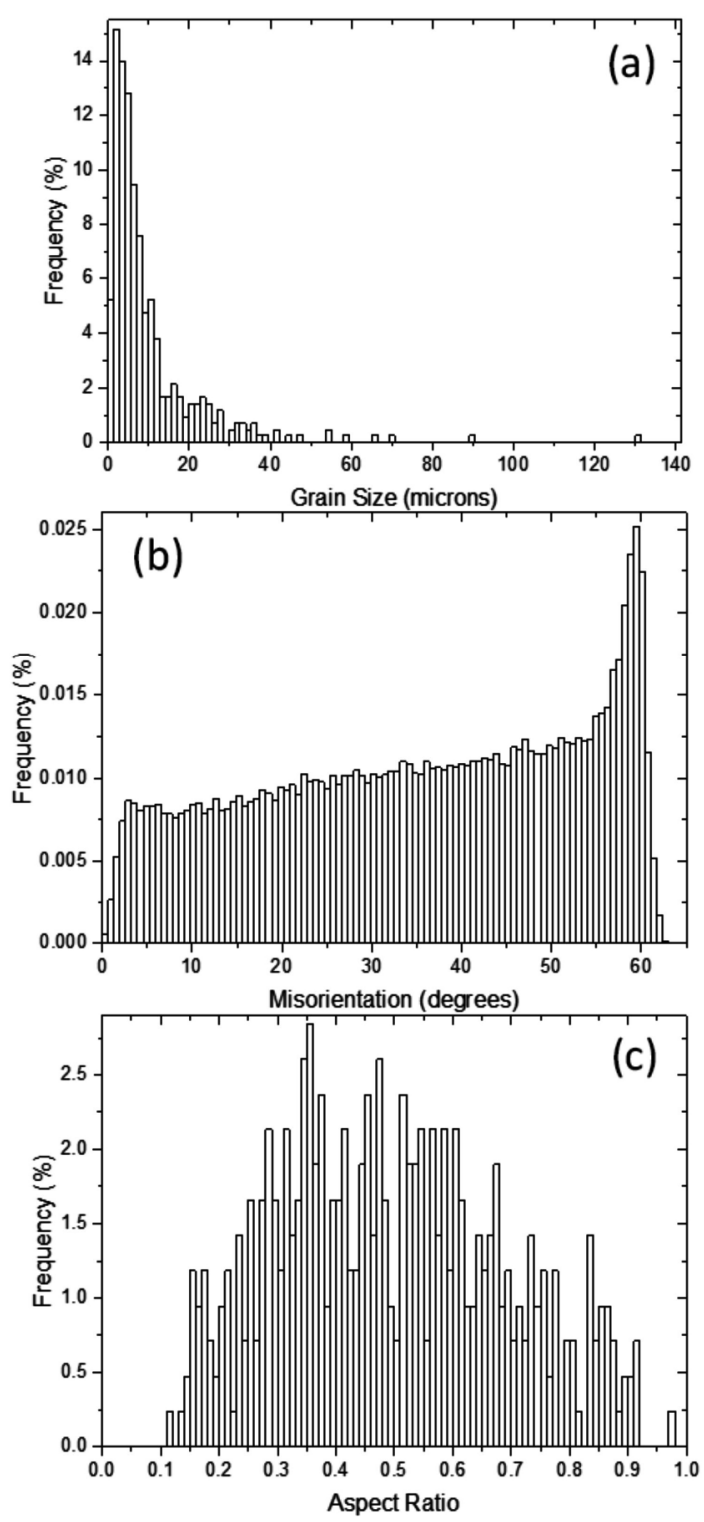

Figure 2. Grain Statistics: (a)Grain size distribution for the region of AA2099-T8 depicted in Figure 1 determined using $\theta>15^{\circ}$ for grain definition. (b) Non-correlated misorientation distribution histogram and

(c) the grain aspect ratio. The aspect ratio should be $<1$ in the extrusion direction. All data is for the aluminium matrix and does not include other phases such as constituent IM particles.

$$
93 \times 190 \mathrm{~mm}(600 \times 600 \mathrm{DPI})
$$



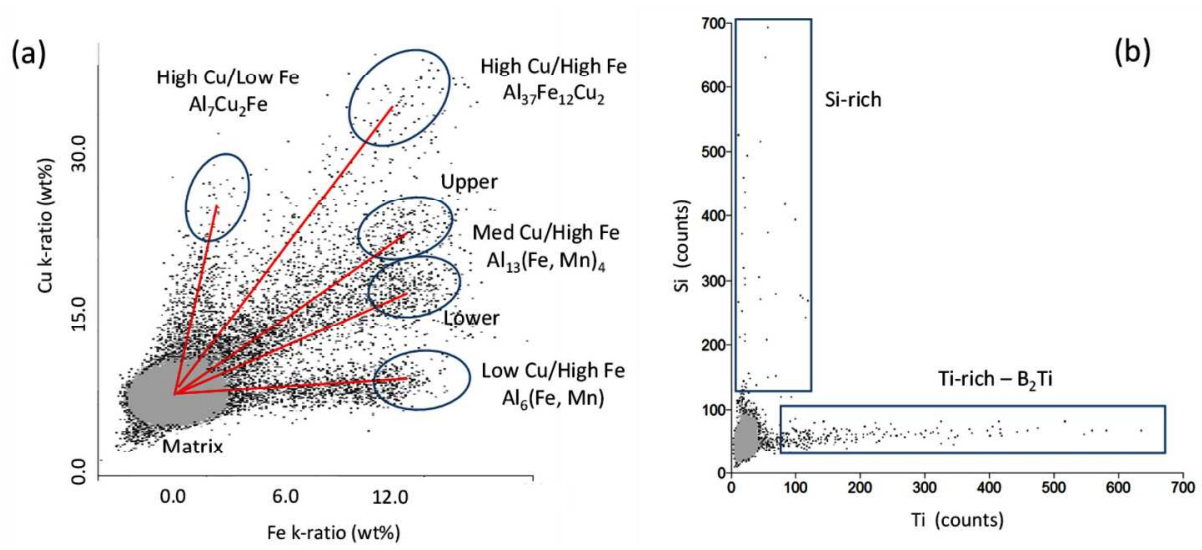

Figure 3. Scatter plots. (a) Cu La - Fe La: The red lines join the centre of the compositions associated with the matrix to the endpoints of each of the five $\mathrm{Cu}-\mathrm{Fe}$ compositions which are indicated in blue ellipses. The major and minor axes of these blue ellipses indicate the likely spread of the data based on two standard deviations. Phase assignments based on EBSD are included in the labelling for each cluster (see below). (b) $\mathrm{Si} \mathrm{Ka}-\mathrm{Ti}$ Ka showing compositions that have higher levels of both $\mathrm{Si}$ and $\mathrm{Ti}$ than that based on alloy addition levels.

207x99mm (300 x 300 DPI) 


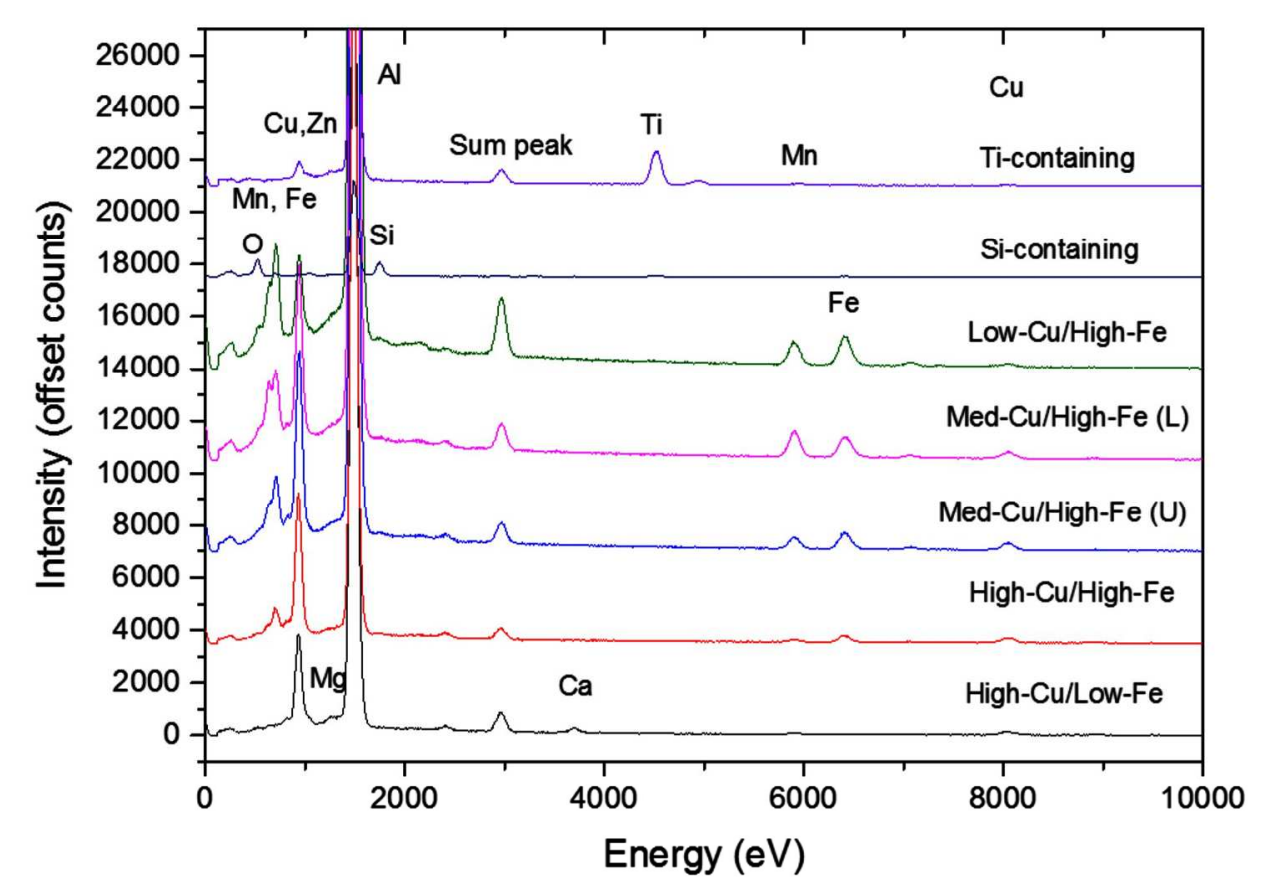

Figure 4. Average spectra for (from bottom to top): High-Cu/Low-Fe, High-Cu/High-Fe, Med-Cu/High-Fe (upper arm), Med-Cu/High-Fe (lower arm), Low-Cu/High-Fe, Si-containing, Ti-containing. L= lower arm and $\mathrm{U}=$ upper arm. All spectra were collected at $10 \mathrm{keV}$.

$173 \times 124 \mathrm{~mm}(300 \times 300 \mathrm{DPI})$ 


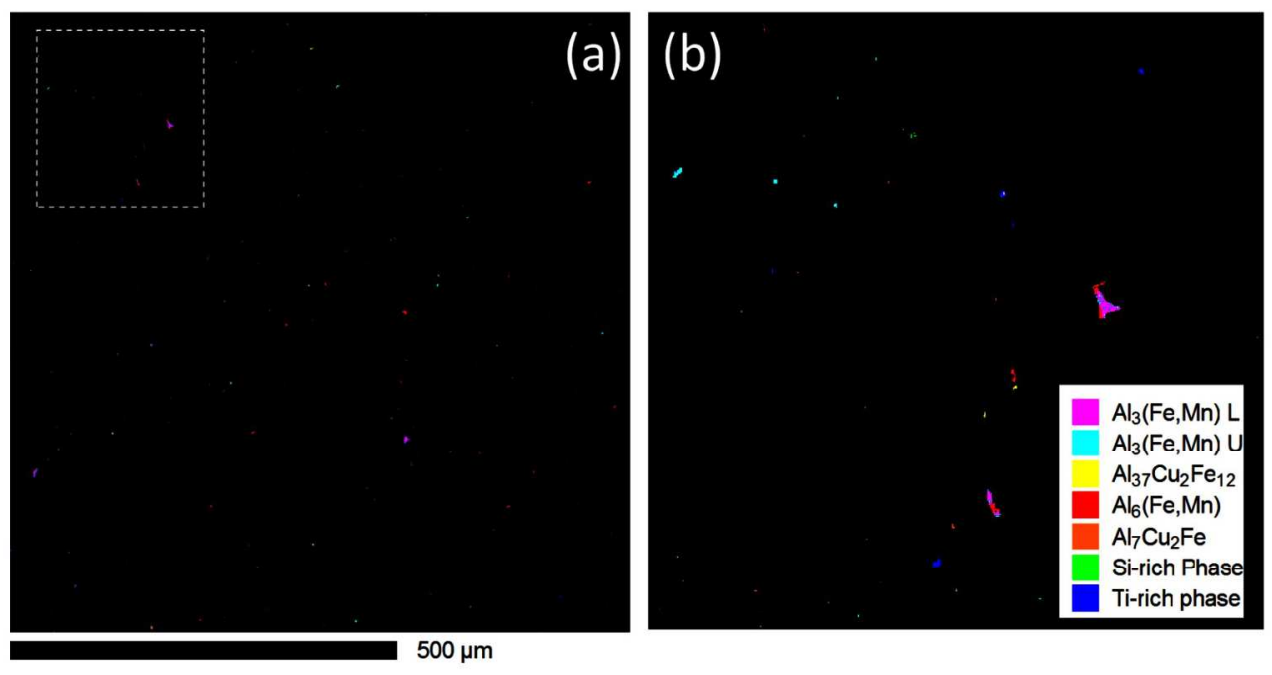

Figure 5. (a) Map of compositional domains over a large area. (b) Magnification of the region within the dashed square indicated in (a) with compositions shown. All the phase are defined from the scatter plots in Figure 3.

$196 \times 105 \mathrm{~mm}(300 \times 300$ DPI $)$ 

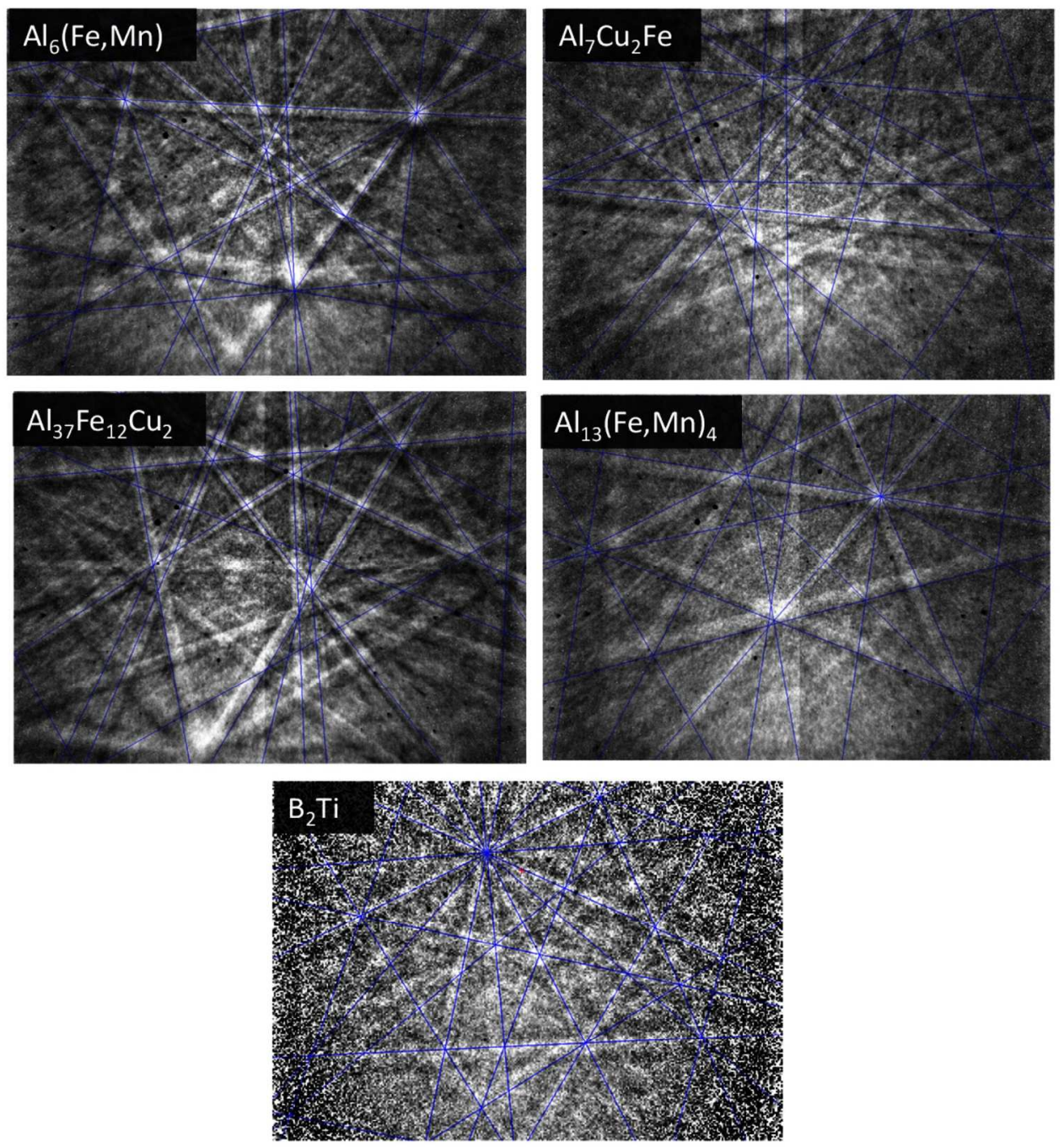

Figure 6. EBSD patterns from various particles or particle domains. The $\mathrm{Al}_{6}(\mathrm{Fe}, \mathrm{Mn})$ is the pattern from the top left intermetallic domain labelled $\mathrm{A}$ in Figure 7, $\mathrm{Al}_{37} \mathrm{Fe}_{12} \mathrm{Cu}_{2}$ is from Region $\mathrm{B}, \mathrm{Al}_{13}(\mathrm{Fe}, \mathrm{Mn})_{4}$ is from the

bottom particle and $\mathrm{Al}_{7} \mathrm{Cu}_{2} \mathrm{Fe}$ is from the small rod-like particle (red) labelled $\mathrm{D}$. All these patterns were obtained by spot analysis on the individual compositional domains for an extended time. The bottom pattern is for a Ti-rich particle and was extracted from a map with overlying $\mathrm{TiB}_{2}$ patterns

$197 \times 210 \mathrm{~mm}(300 \times 300$ DPI $)$ 


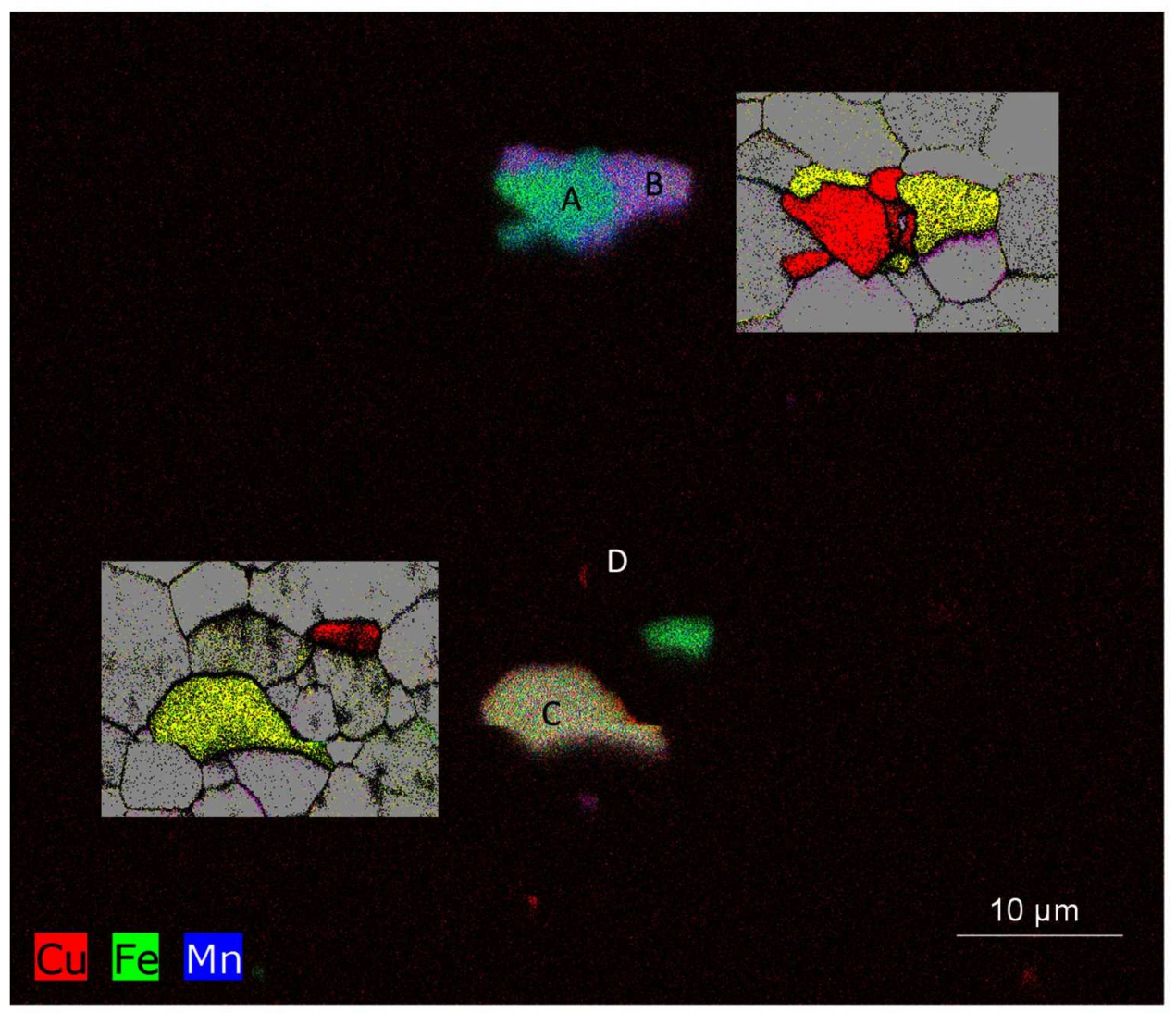

Figure 7. Three colour EDS elemental maps for $\mathrm{Cu}$, Fe and $\mathrm{Mn}$. Inserts are EBSD maps for the larger particles. Magenta represents $\mathrm{Al}_{13}(\mathrm{Fe}, \mathrm{Mn})_{4}$, grey represents $\mathrm{Al}_{6}(\mathrm{Fe}, \mathrm{Mn})$ composition and yellow is a-Al. $197 \times 170 \mathrm{~mm}(300 \times 300$ DPI $)$ 


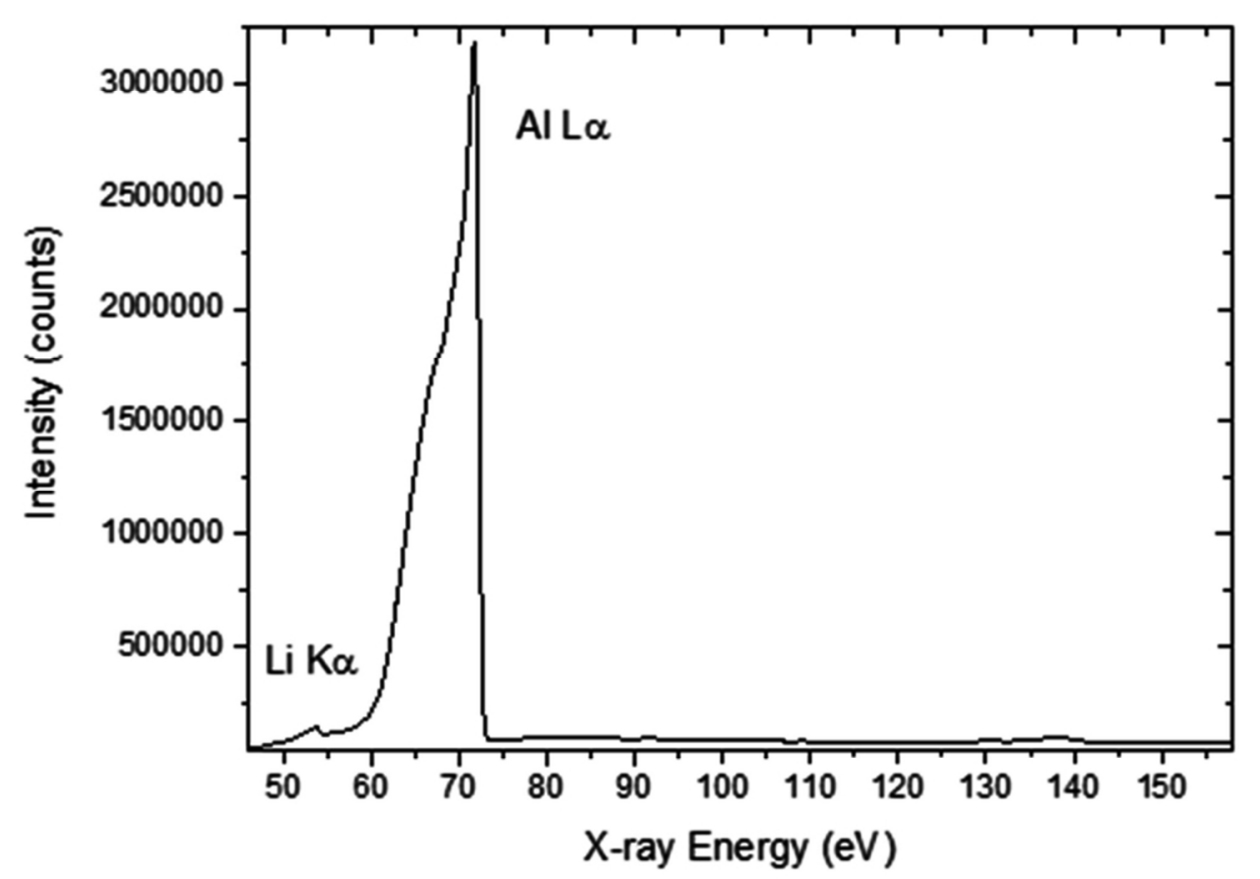

Figure 8. Sum soft X-ray spectrum of AA2099-T8 showing Li K and Al L Fermi edges. The small peak at $137 \mathrm{eV}$ is associated with a second order reflection of the $\mathrm{C} \mathrm{K}$ line.

$$
45 \times 32 \mathrm{~mm}(600 \times 600 \mathrm{DPI})
$$



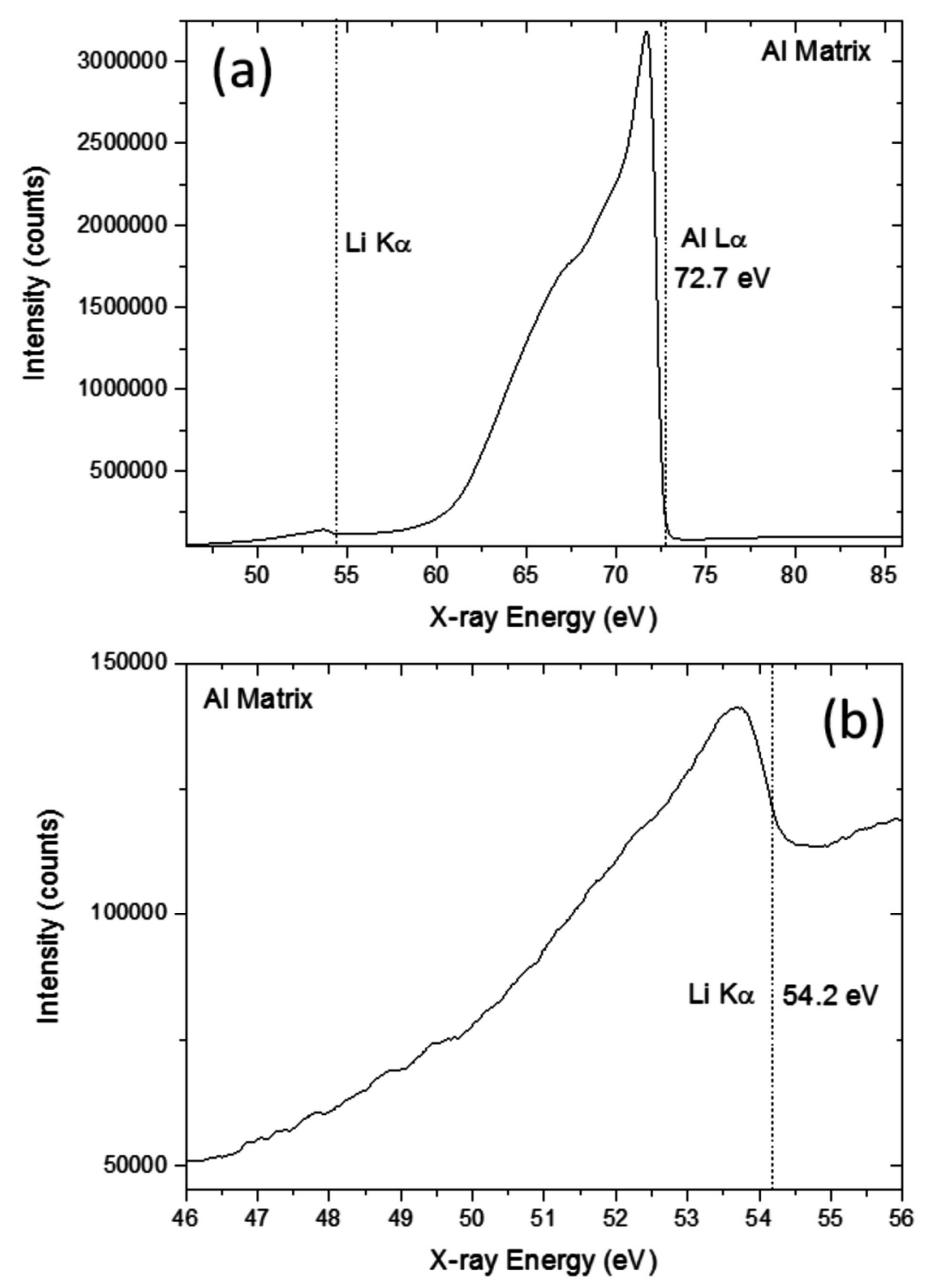

Figure 9. Soft X-ray spectra of (a) Al-Li region and (b) Magnification of the Li region (Ka). The Li spectrum has been smoothed using adjacent averaging over 5 points (i.e. \pm 2 points).

$78 \times 110 \mathrm{~mm}(600 \times 600 \mathrm{DPI})$ 


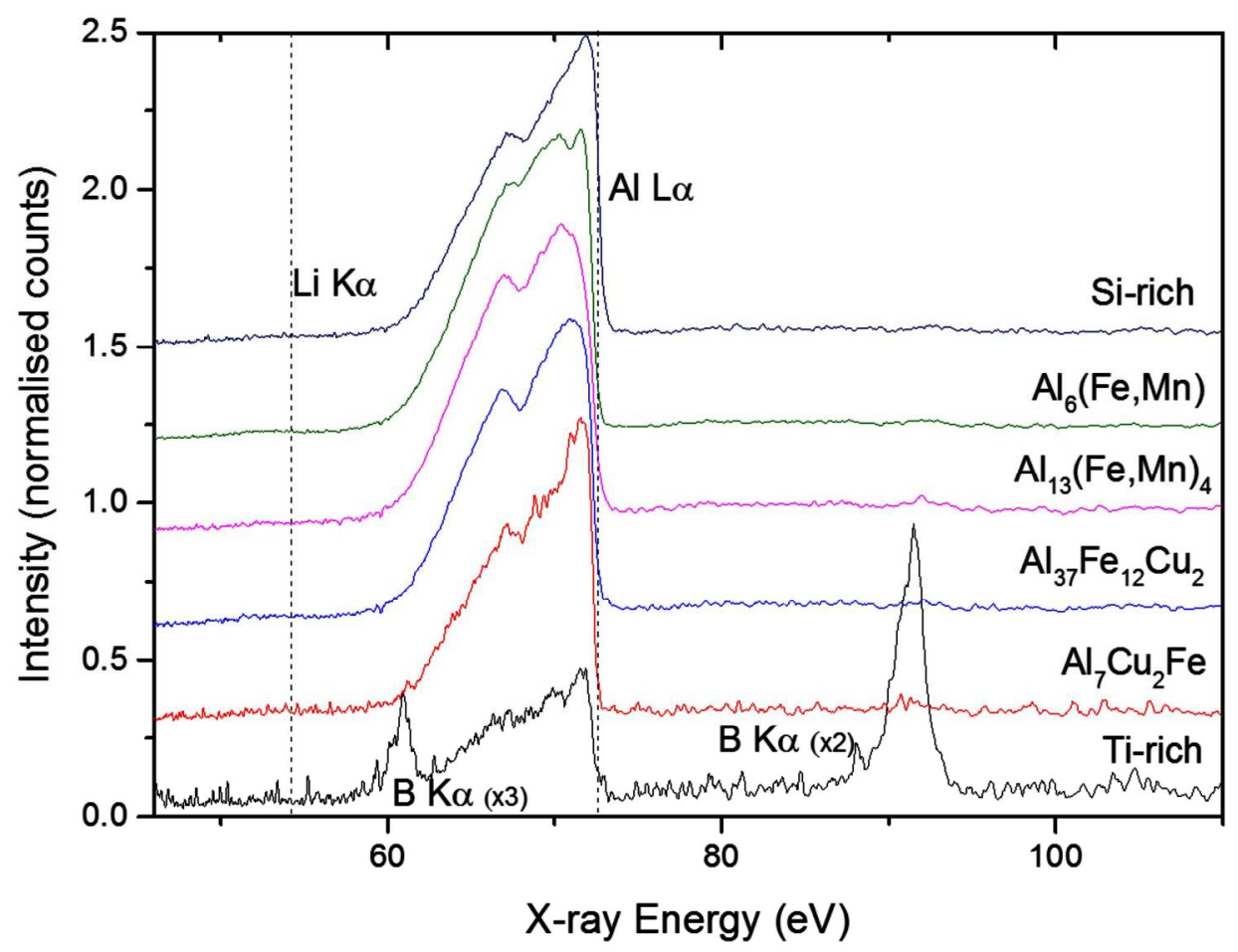

Figure 10. Soft X-ray Li and Al spectra from different IM compositions. The SXES spectra has been smoothed using adjacent averaging extending over \pm 2 points).

$$
180 \times 139 \mathrm{~mm}(300 \times 300 \text { DPI })
$$




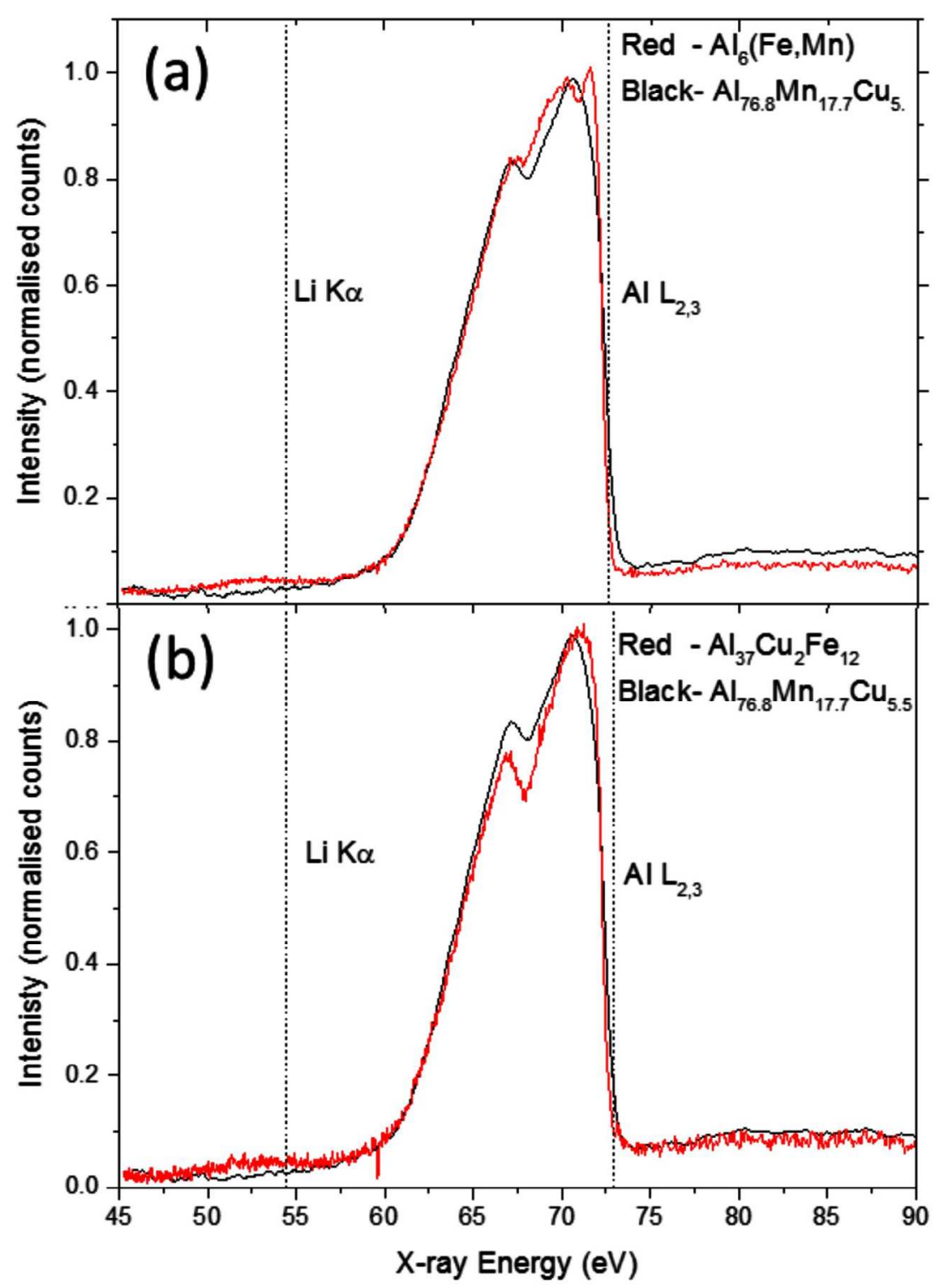

Figure 11. SXES spectra of two types of (a) $\mathrm{Al}_{6}\left(\mathrm{Fe}, \mathrm{Mn}\right.$ ) and (b) $\mathrm{Al}_{37} \mathrm{Fe}_{12} \mathrm{Cu}_{2}$ from the $\mathrm{AA2099}$ compared (in both cases) with $\mathrm{Al}_{76.8} \mathrm{Mn}_{17.7} \mathrm{Cu} 5.5$. The SXES of the IM particles from the AA2099 show evidence of Li which is not present in the reference phase $\left(\mathrm{Al}_{76.8} \mathrm{Mn}_{17.7} \mathrm{Cu}_{5.5}\right)$.

$152 \times 204 \mathrm{~mm}(300 \times 300$ DPI) 

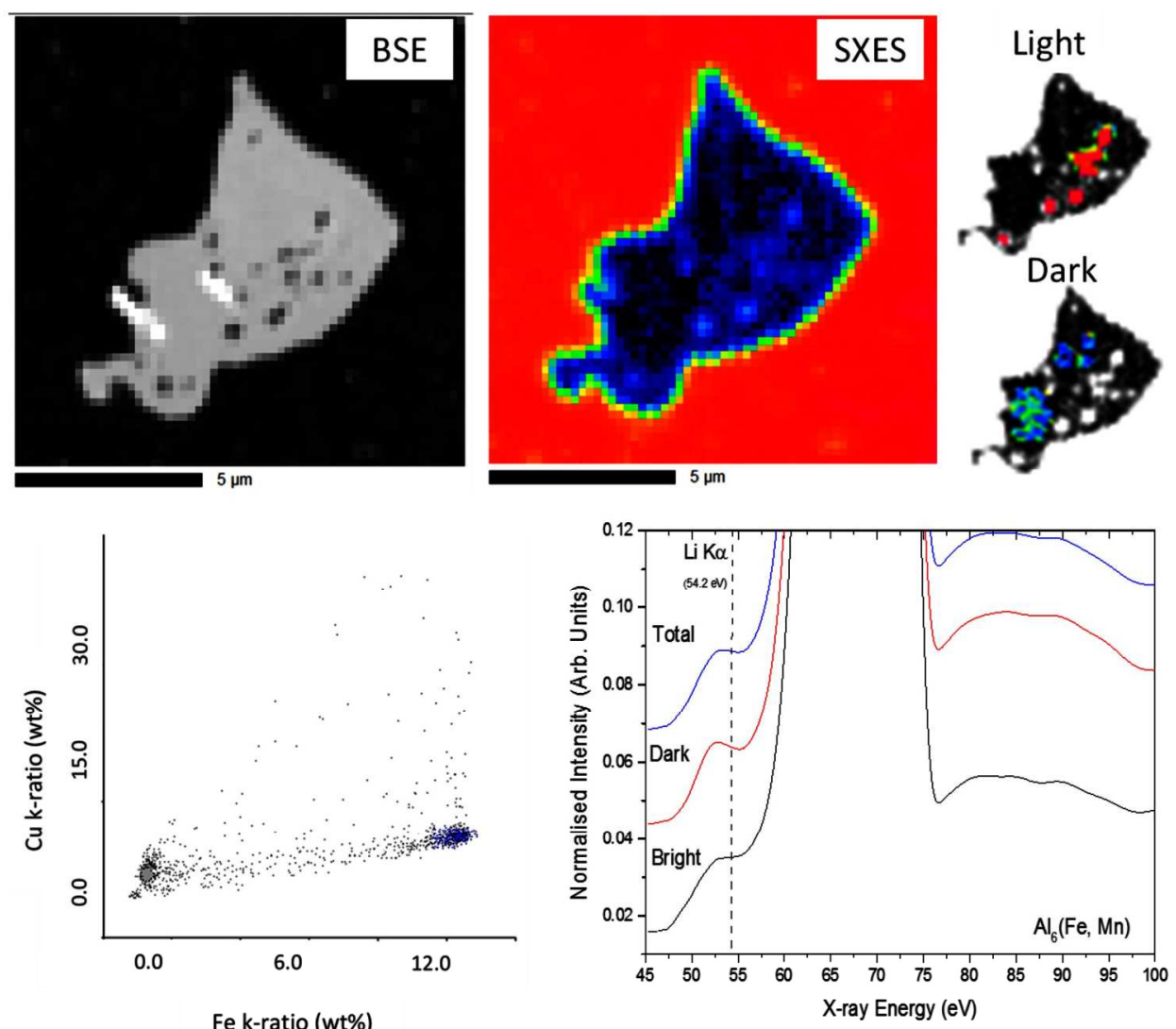

Fe k-ratio (wt\%)

Figure 12. Variation in $\mathrm{Li}$ content in $\mathrm{Al}_{6}(\mathrm{Fe}, \mathrm{Mn})$. The BSE image shows some bright regions related to $\mathrm{Al}_{13}$ $(\mathrm{Fe}, \mathrm{Mn})_{4}$ domains, grey regions and dark areas. The regions of analysis where these spectra were collected as displayed by the colour on the small maps at the top right. Total SXES intensity shows light blue to black contrast within the IM particle even within regions of even BSE contrast. The SXE spectra show that the dark regions have higher levels of $\mathrm{Li}$ than the rest of the $\mathrm{IM}$ particles excluding the $\mathrm{Al}_{13}(\mathrm{Fe}, \mathrm{Mn})_{4}$ domains.

$185 \times 164 \mathrm{~mm}(300 \times 300 \mathrm{DPI})$ 

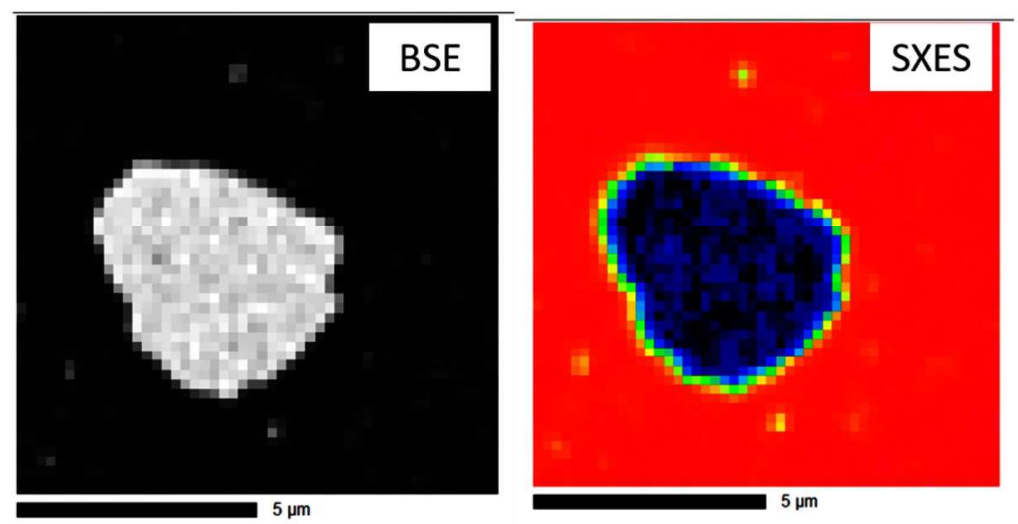

Light

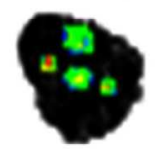

Dark
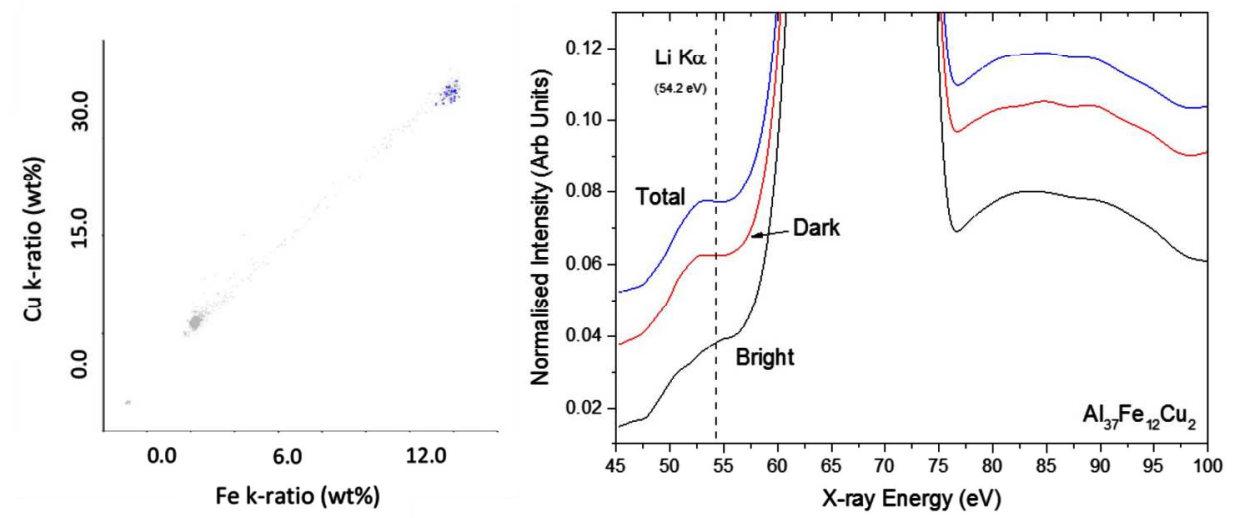

Figure 13. Variation in $\mathrm{Li}$ content in $\mathrm{Al}_{37} \mathrm{Fe}_{12} \mathrm{Cu}_{2}$. The backscatter (BSE) image shows some bright areas and dark areas. The regions of analysis where these spectra were collected as displayed by the colour on the small maps at the top right. Total SXES intensity shows light blue to black contrast within the IM particles even within regions of contrast in the BSE image. The SXE spectra show that the dark regions have higher levels of $\mathrm{Li}$ and the brighter regions.

$185 \times 160 \mathrm{~mm}(300 \times 300$ DPI $)$ 

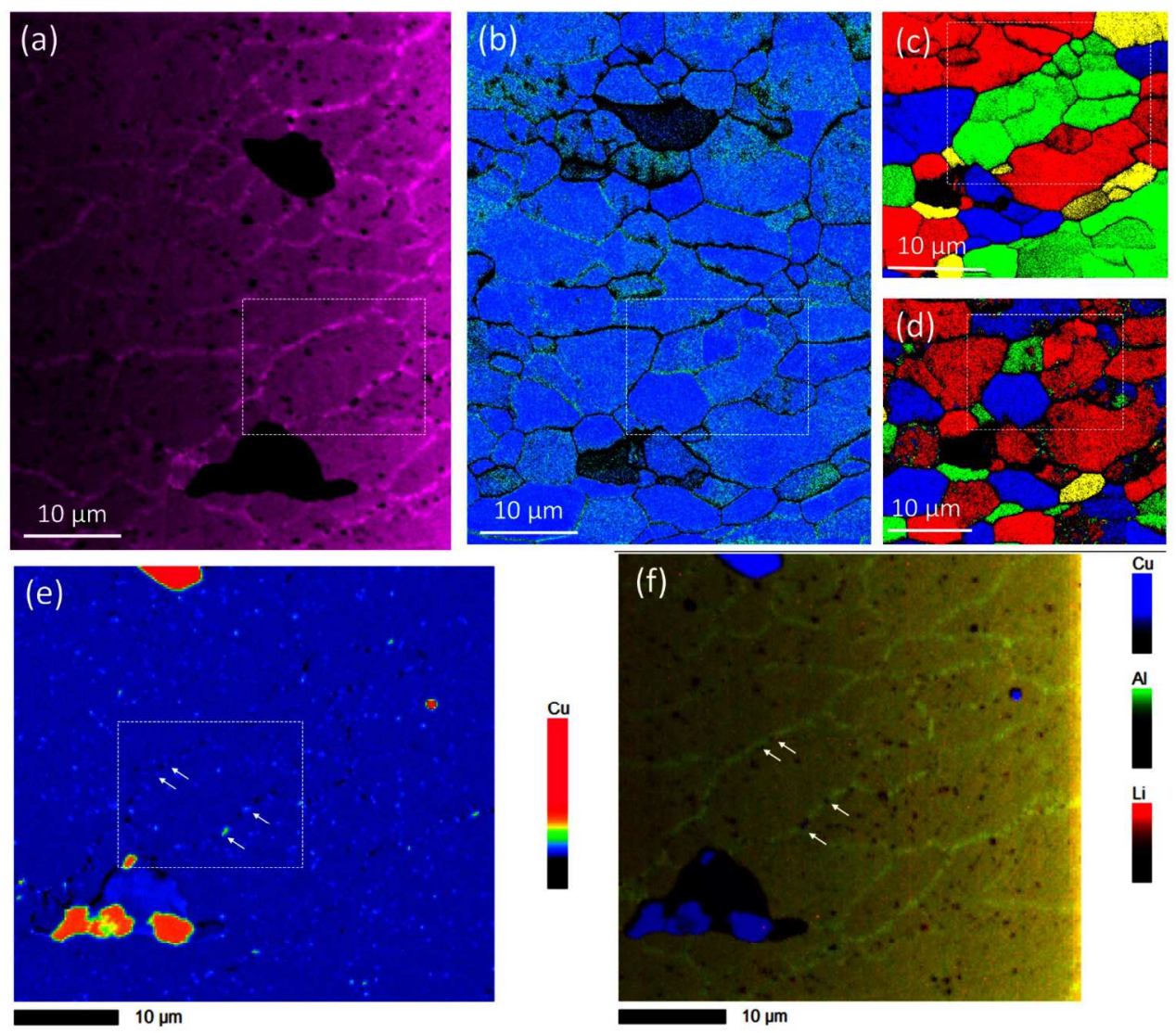

Figure 14. Mixed SXES, EDS, WDS and EBSD data (a) Al La map and (b) KAM maps with the dashed rectangle highlighting a large grain near the constituent IM particle. (c) EBSD grain map with HAGBs (in this case $\left.\theta>9^{\circ}\right)$ (d) EBSD grain map for LAGBs $\left(\theta=0.5^{\circ}\right)$, (e) Cu La EDS map highlighting the presence of $\mathrm{Cu}$ particles decorating the grain boundary, (f) Cu La EDS, Al La (SXES), and Li Ka (SXES) 3-colour image incorporating The microprobe data were collected on the same area, but after a light polish to remove carbon contamination. White arrows point to T1 precipitates.

$195 \times 173 \mathrm{~mm}(300 \times 300$ DPI $)$ 

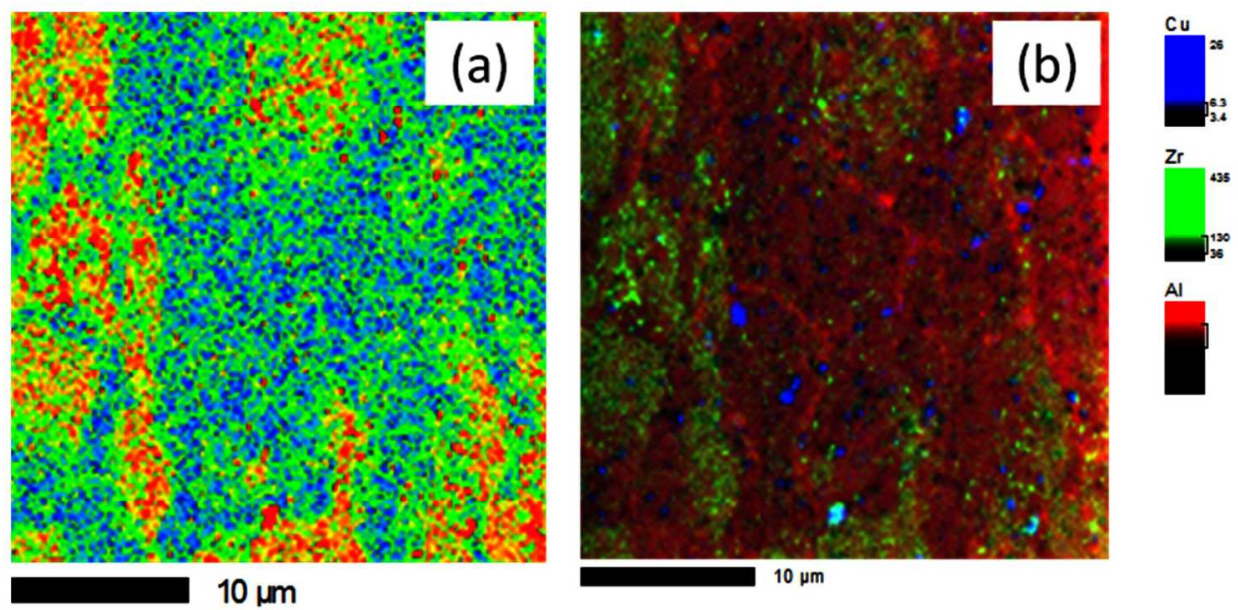

Figure 15. Mixed EDS, WDS and Soft X-ray maps. (a) Zr La map, (b) 3-colour image incorporating Cu La (EDS), Zr La (SXES) and Al La (SXES), (EDS).

$197 \times 99 \mathrm{~mm}(300 \times 300 \mathrm{DPI})$ 


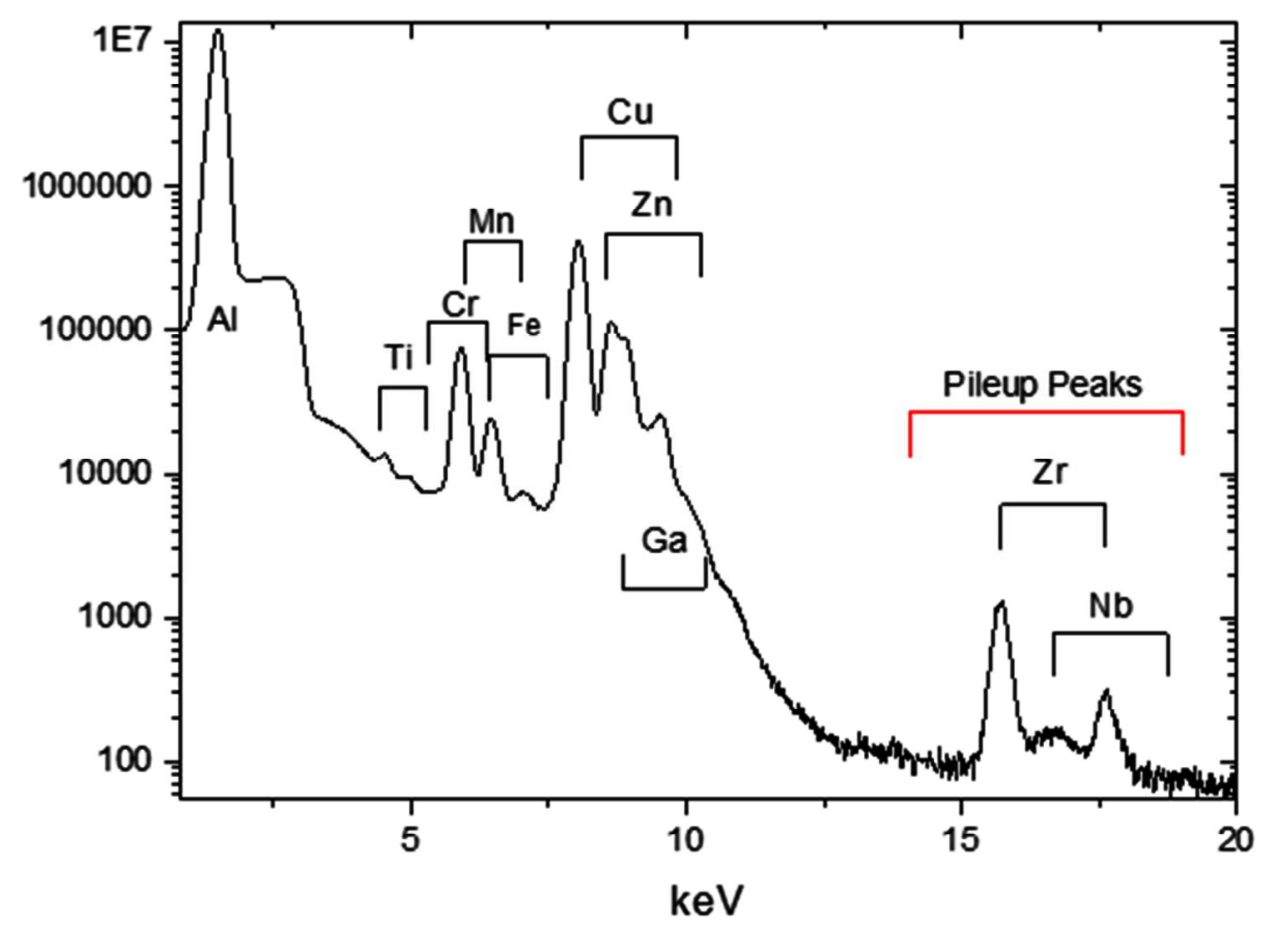

Figure 16. PIXE spectrum. The markers beneath the elemental identification indicate the position of the two major peaks for the element ( $\mathrm{Ka}$ and $\mathrm{K} \beta$ lines). The red marker indicates where there is a relevant pile-up contribution to the spectrum. There is also pileup elsewhere in the spectrum but it is several orders of magnitude smaller than the signal.

$192 \times 147 \mathrm{~mm}(300 \times 300 \mathrm{DPI})$ 


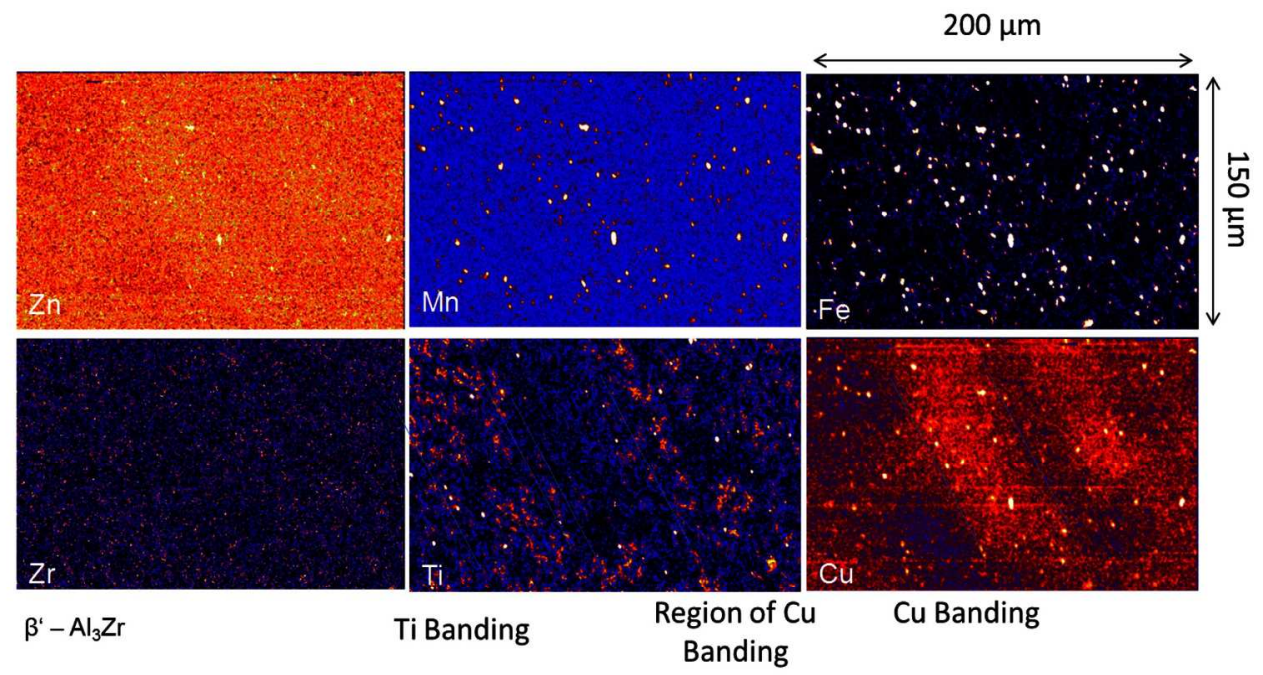

Figure 17. $\mathrm{Zn}, \mathrm{Mn}, \mathrm{Fe}, \mathrm{Zr}, \mathrm{Ti}$ and $\mathrm{Cu}$ PIXE maps of AA2099-T8. The $\mathrm{Cu}$ and Ti maps show evidence of banding. In the case of $\mathrm{Cu}$ there appears to be a high density of $\mathrm{Cu}$-containing particles whereas in the case of $\mathrm{Ti}$ the bands comprise Ti-containing particles.

$195 \times 111 \mathrm{~mm}(300 \times 300$ DPI) 